\title{
Monitoring and Evaluation of the Emergency Plan Progress (MEEPP): End-of-project evaluation
}

Sam Kalibala

Population Council

Follow this and additional works at: https://knowledgecommons.popcouncil.org/departments_sbsr-hiv

Part of the Demography, Population, and Ecology Commons, Health Services Research Commons, Immune System Diseases Commons, International Public Health Commons, Medicine and Health Commons, Quantitative, Qualitative, Comparative, and Historical Methodologies Commons, and the Virus Diseases Commons How does access to this work benefit you? Let us know!

\section{Recommended Citation}

Kalibala, Sam. 2010. "Monitoring and Evaluation of the Emergency Plan Progress (MEEPP): End-of-project evaluation." New York: Population Council. 


\section{Monitoring and Evaluation of the Emergency Plan Progress (MEEPP): End-of-Project Evaluation}

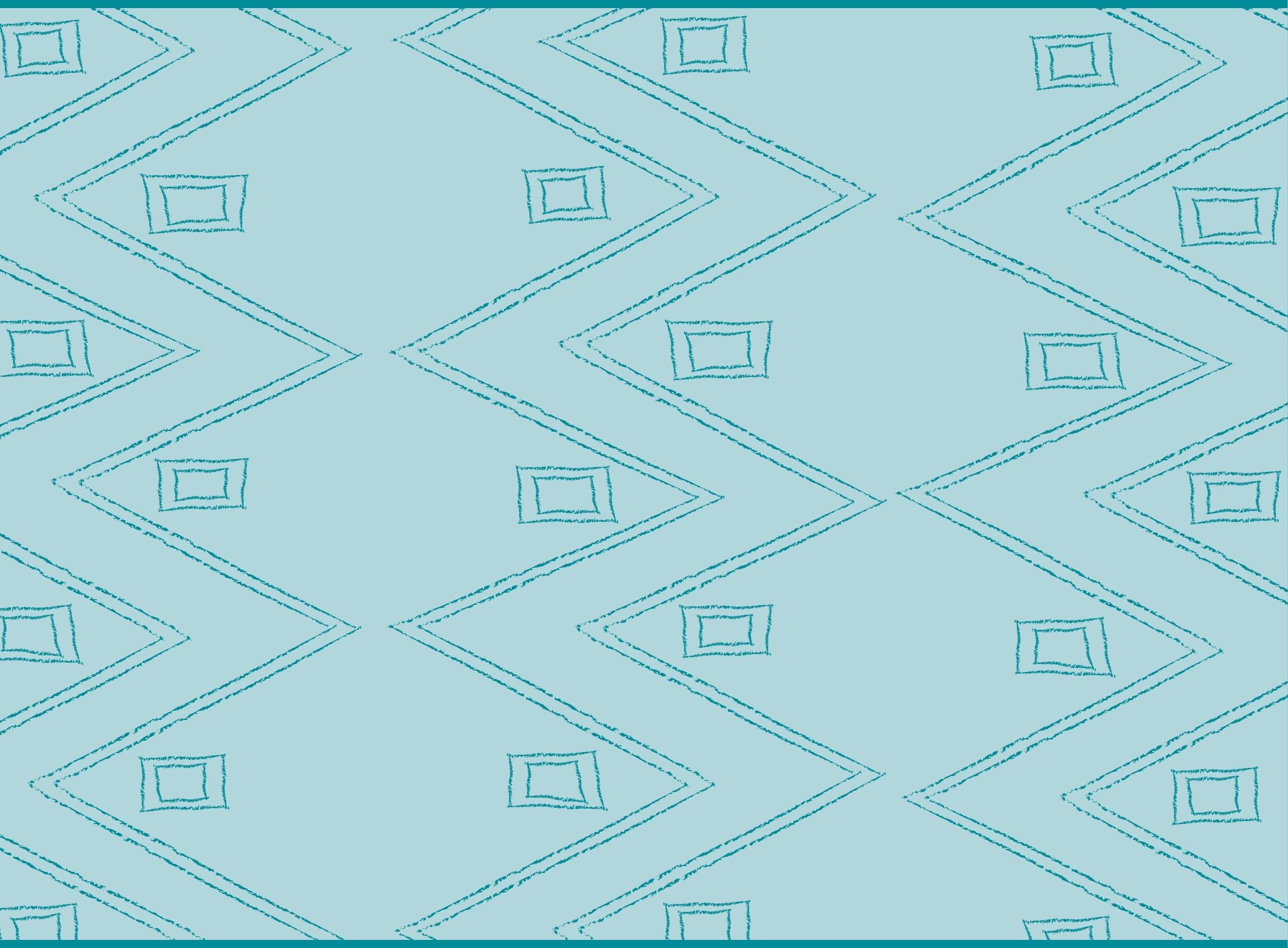





\title{
Monitoring and Evaluation of the Emergency Plan Progress (MEEPP): End-of-Project Evaluation
}

\author{
Samuel Kalibala
}

Population Council

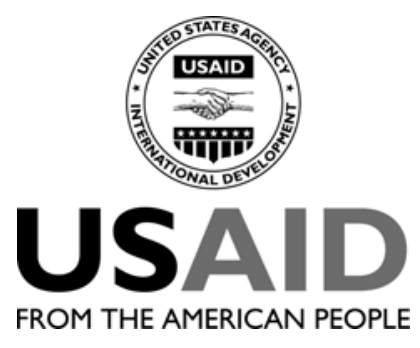




\section{Acknowledgements}

The evaluation of the Monitoring and Evaluation of the Emergency Plan Progress (MEEPP) project was made possible with support from the United States Agency for International Development (USAID)/Uganda.

This report was written by Dr. Sam Kalibala of the Population Council. The author is grateful to Dr. Paul Bukuluki and Richard Tuyiragize for their contributions in leading the data collection process, analyzing the data, and reviewing the report, and to the data collection team: Ronald Mukuye, David Mugisa, Esther Nassonko, and Anthony Begumisa.

The author also thanks several Population Council colleagues for their inputs at various stages of the process: Dr. Robert Miller and Deborah Weiss for their review of this report; Hena Khan for editing; Sherry Hutchinson for layout; and Norah Omenda for administrative and logistics support.

Finally, special thanks to the participants in the evaluation, including representatives from the Government of Uganda, the PEPFAR Country Team, the staff of MEEPP, and the prime partners and sub-grantee implementing partners, for sharing their perspectives on MEEPP and broader HIV monitoring and evaluation activities in Uganda. Contract No. GHH-I-02-07-00034-00. The contents are the responsibility of the authors and do not necessarily reflect the views of USAID or the United States Government.

The Population Council conducts research worldwide to improve policies, programs, and products in three areas: HIV and AIDS; poverty, gender, and youth; and reproductive health. www.popcouncil.org

Published in January 2010.

Copyright @ 2010 . United States Agency for International Development.

Suggested citation: Kalibala, Samuel. 2010. "Monitoring and Evaluation of the Emergency Plan Progress (MEEPP): End-of-project evaluation,” Final Report. New York: Population Council.

This document may be reproduced in whole or in part without permission of the Population Council provided full source citation is given and the reproduction is not for commercial purposes. 


\section{Table of Contents}

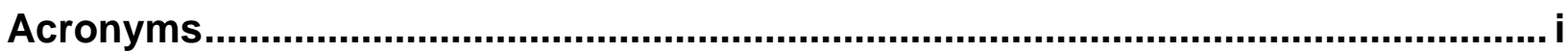

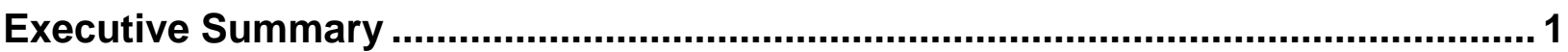

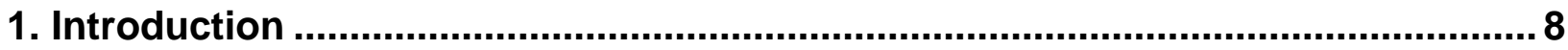

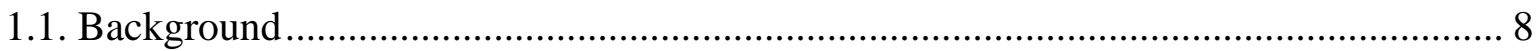

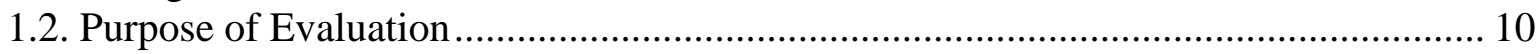

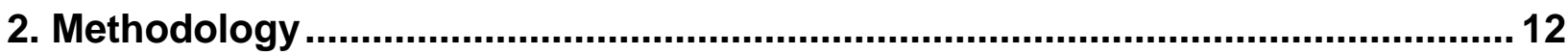

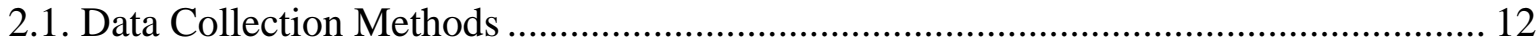

2.2. Data Analysis and Management …………………................................................. 15

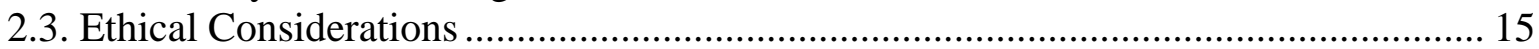

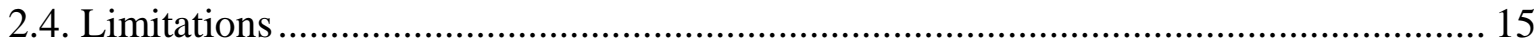

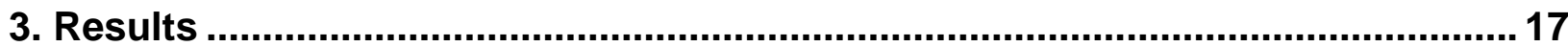

3.1. Overall, was the MEEPP design able to address the M\&E needs of PEPFAR and

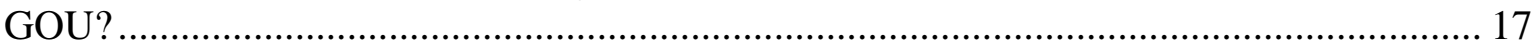

3.2. Overall, was MEEPP implemented as designed? ....................................................... 18

3.3. What has been the trend of quality of data reported to OGAC over the last five

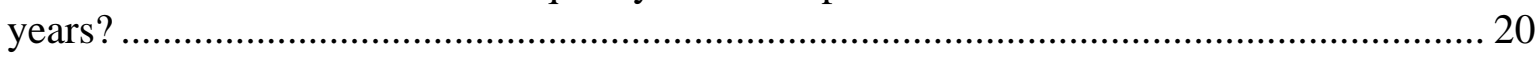

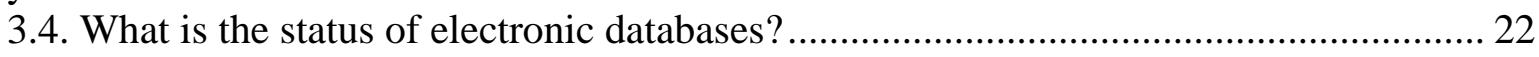

3.5. What has been the effects/impact of MEEPP on the reporting capacity of PEPFAR-

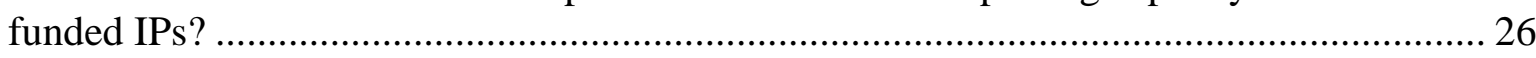

3.6. What has been the effects/impact of the MEEPP project on the national M\&E

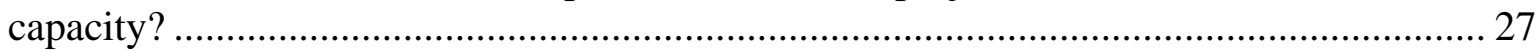

3.7. In summary, what are the lessons that can be learned? ............................................. 28

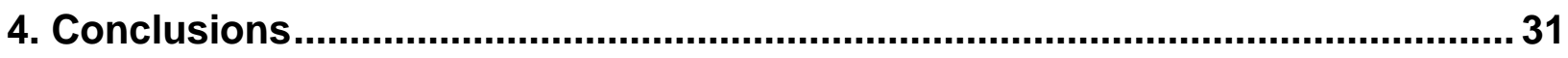

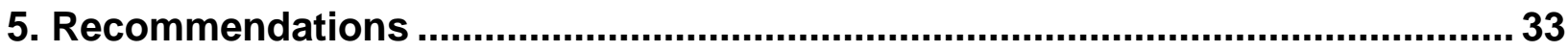

Appendix 1: Documents Reviewed........................................................................ 36

Appendix 2: Questionnaires........................................................................... 38

Master Guide for Key Informant Interviews and In-depth Interviews ............................... 38

Checklist for Observation of Data Management System.................................................... 41

Appendix 3: Prime Partners .................................................................................. 43

Appendix 4: Matrix for Selecting Prime Partners and Implementing Partners Sample 



\section{Acronyms}

$\begin{array}{ll}\text { ACP } & \text { AIDS Control Program } \\ \text { AIDS } & \text { Acquired Immunodeficiency Syndrome } \\ \text { CDC } & \text { US Centers for Disease Control and Prevention } \\ \text { COP } & \text { Country Operational Planning } \\ \text { COTR } & \text { Contracting Officer Technical Representative } \\ \text { DQA } & \text { Data Quality Assurance } \\ \text { FY } & \text { Fiscal Year } \\ \text { GOU } & \text { Government of Uganda } \\ \text { NIH } & \text { US National Institutes of Health } \\ \text { HIV } & \text { Human Immunodeficiency Virus } \\ \text { HMIS } & \text { Health Management Information System } \\ \text { IDI } & \text { In-Depth Interview } \\ \text { IP } & \text { Implementing Partner } \\ \text { KII } & \text { Key Informant Interview } \\ \text { MEEPP } & \text { Monitoring and Evaluation of Emergency Plan Progress } \\ \text { M\&E } & \text { Monitoring and Evaluation } \\ \text { MEMS } & \text { Monitoring and Evaluation Management Services } \\ \text { MOH } & \text { Ministry of Health } \\ \text { MGLSD } & \text { Ministry of Gender, Labor, and Social Development } \\ \text { OGAC } & \text { Office of the US Global AIDS Coordinator } \\ \text { OVC } & \text { Orphans and Vulnerable Children } \\ \text { PEPFAR } & \text { US President's Emergency Plan for AIDS Relief } \\ \text { PMTCT } & \text { Prevention of Mother-to-Child Transmission } \\ \text { SI } & \text { Strategic Information } \\ \text { TASO } & \text { The AIDS Support Organization } \\ \text { TWG } & \text { Technical Working Group } \\ \text { USAID } & \text { United States Agency for International Development } \\ \text { UAC } & \text { Uganda AIDS Commission } \\ \text { USG } & \text { United States Government }\end{array}$





\section{Executive Summary}

\section{Introduction}

The U.S. President's Emergency Plan for AIDS Relief (PEPFAR) supports a comprehensive HIV/AIDS prevention, care, and treatment program in Uganda. PEPFAR funds more than 80 percent of HIV/AIDS activities in Uganda through implementing partners (IPs), including 70 prime partners, which receive direct grants from PEPFAR, and which in turn sub-grant about 1,000 HIV/AIDS organizations.

The Monitoring and Evaluation of the Emergency Plan Progress (MEEPP) is a United States Agency for International Development (USAID)/Uganda-funded project that has been implemented by Social \& Scientific Systems, Inc. since December 2004. MEEPP was designed to achieve the following results: 1) improved availability of PEPFAR data; 2) improved quality of PEPFAR data; 3) improved monitoring and evaluation (M\&E) capacity for PEPFAR-funded partners; and 4) improved coordinated response.

MEEPP has established and operates a data management system to collate, clean, validate, and analyze service output data of PEPFAR-funded partners, and submit them to the PEPFAR Country Team in Uganda. The prime partners collate data provided to them by IPs located in the periphery. MEEPP receives data that are uploaded online. To ensure data quality, the US Government (USG) Technical Working Groups (TWGs) and MEEPP provide capacity building on PEPFAR reporting requirements to prime partners and carry out data quality assurance (DQA), which involves cleaning and validating the data as they are being entered and afterwards. MEEPP also provides feedback to IPs in meetings about the quality of their data as well as scheduled and on-demand visits to carry out on-site DQA.

\section{Purpose of the Evaluation}

In August 2009, the Population Council was contracted by USAID/Uganda to evaluate MEEPP. The purpose of the evaluation, as stated in the scope of work, was to determine lessons learned, and to critically examine the aspects of the project that may need change in order to address gaps, namely, national M\&E system's development and capacity building for host-country M\&E and other specialists. The evaluation was designed to answer seven questions: 1) Was the MEEPP design able to address the M\&E needs of PEPFAR and the Government of Uganda (GOU)? 2) Was the MEEPP project implemented as designed? 3) Did the quality of PEPFAR data improve? 4) What is the status of the electronic database of PEPFAR data? 5) What was the impact of MEEPP on the M\&E capacity of PEPFAR-funded implementing partners? 6) What was the impact of MEEPP on national M\&E capacity? 7) What were the lessons learned and aspects that may need change? 


\section{Methodology}

The analytical framework for this evaluation was based on two basic principles: a) the purpose of the evaluation and the seven evaluation questions as stated scope of work; and b) the mandate of MEEPP as stated in the four major results. The evaluation used four data collection methods: a literature review, key informant interviews (KIIs), in-depth interviews (IDIs), and observation of data management systems. A total of 23 KIIs were conducted with respondents from the USG PEPFAR Country Team, USG TWGs, USAID Monitoring and Evaluation Management Services (MEMS), the Ministry of Health (MOH), the Uganda AIDS Commission (UAC), the Ministry of Education and Sports, and the Ministry of Gender, Labor and Social Development (MGLSD). IDIs were conducted with respondents from 18 PEPFAR-funded prime partners and 14 sub-grantees (see Appendix 4). Six IDIs were conducted with respondents from district health offices. Observations of data management systems were carried out at the offices of MEEPP, two prime partners, one sub-grantee IP for each of the prime partners, UAC, and the MOH Resource Center.

The literature review was used to generate tentative findings under each evaluation question and included: quarterly reports of MEEPP performance, as well as explanatory notes that MEEPP produced to accompany its semi-annual and annual reports, and reports of aggregate service delivery data compiled according to specific USG funding agencies (Centers for Disease Control and Prevention, USAID, Department of State, National Institutes of Health (NIH), Peace Corps, and Department of Defense). The evaluation team also reviewed PowerPoint presentations summarizing the MEEPP project as well as the DQA process, and a report detailing the DQA conducted for a prime partner. Finally, the team reviewed literature about PEPFAR-funded activities in Uganda obtained from the PEPFAR website.

Data from IDIs, KIIs, and observations of data management systems were used to validate the tentative findings from the literature review. Data collection and analysis ran concurrently. The evaluation team held de-briefing meetings every two days to identify main emerging themes, which were shared with USAID staff, the PEPFAR Country Team, and then with MEEPP. Through this process a list of recommendations for changes in the MEEPP followon project were developed and discussed.

\section{Results}

Results are presented in accordance with the seven evaluation questions.

\section{Overall, was the MEEPP design able to address the M\&E needs of PEPFAR and GOU?}

The MEEPP design was able to meet the reporting requirements of PEPFAR, providing rapid reporting of outputs using up-to-date indicators. However, USG respondents underscored that MEEPP was never intended to address the M\&E needs of GOU. Instead, USG procured other means of technical assistance to UAC and MOH/Resource Center, while MEEPP was expected to work with USG to provide clean, unduplicated data on PEPFAR-funded activities 
that contribute to the results of the national HIV/AIDS response. However, the MEEPP design and operation does not involve a structured approach to strengthen national M\&E systems nor to ensure harmonization, aggregation, and coordination with GOU. GOU respondents indicated that MEEPP should have been embedded in a GOU agency in order for it to work synergistically with GOU M\&E efforts. Instead, MEEPP undermined the functionality of GOU M\&E systems because MEEPP commands the vast majority of HIV program data in the country.

\section{Overall, was the MEEPP project implemented as designed?}

MEEPP was implemented as designed, i.e., to provide the PEPFAR Country Team with timely, high quality output data from the prime partners which received data from their subgrantee IPs. Since early 2005, the USG TWGs and MEEPP have consistently produced the required semi-annual and annual program reports. Once the data are analyzed, MEEPP posts reports on the website which can be accessed, using passwords, by USG agencies, prime partners, and personnel of selected relevant GOU agencies. However, this design is not without consequences: tight PEPFAR deadlines require that both MEEPP and prime partners suspend other M\&E activities during the three-week data entry period. In addition, subgrantee IPs have different capacities to deliver their data to prime partners.

Data generated by MEEPP are intended to be used to strengthen PEPFAR programming in Uganda. On a strategic planning level, MEEPP provides data, including ad hoc analyses, to assess progress and to facilitate the Country Operational Planning (COP) process. At the program implementation level, the data are used to assist individual IPs to improve their performance and to encourage partners to seek synergies. Host country policy makers also reported using MEEPP data, but in a less structured process, for example, to prepare the Global Fund application in 2007 and the National Strategic Plan in 2008.

\section{What has been the trend of quality of data reported to OGAC over the last five years?}

USG respondents were satisfied with the quality of data that PEPFAR/Uganda reported to OGAC, to the credit of MEEPP. MEEPP has strengthened the capacity of prime partners through DQA and feedback on quality of data. However, there are a number of issues that continue to adversely affect the quality of data. The absence of national identity cards limits the effectiveness of the unique identifier number strategy. Despite efforts to coordinate among USG agencies, multiple PEPFAR-funded IPs provide the same type of service (e.g., HIV counseling and testing) in one facility, which results in duplication if clients receive the same service from more than one IP at that site. Other factors affecting data quality include the short deadlines for prime partners to enter data, which do not always allow sufficient time to verify and clean data; changes in PEPFAR indicators on short notice, which preclude some IPs from reporting on them; and challenges related to prevention interventions that use mass media and can only be reported using estimates. It should also be noted that some of the IPs are constrained by staff shortages and although this may affect the quality and timeliness of data, it is beyond the mandate of MEEPP to address this issue. 


\section{What is the status of the electronic database of PEPFAR data?}

MEEPP has upgraded its database technology to ensure compatibility with various internet browsers. While the database is easily accessible to prime partners during the data entry periods, slow internet connections require some prime partners to work at night and/or go to the MEEPP offices to enter the data. With regard to inter-operability of data-based systems, the MEEPP system is adaptable to GOU and other stakeholder needs since many of the indicators are similar or relate to national indicators. However, the HMIS is not compatible with MEEPP.

According to staff of USG and of prime partners, the database is user-friendly and is being utilized by stakeholders. The prime partners, USG staff, and GOU agencies have access to the database, using passwords, at all times and can download reports. However, MEEPP respondents indicated that a number of users find excuses, such as loss of passwords, to avoid accessing the database directly, and instead request data from MEEPP. In addition, some stakeholders reported that the customized reports are insufficiently detailed for decision making and planning purposes - a reason for requests for further analyses. The data are also only available on a semi-annual and annual basis, yet a number of stakeholders seek monthly or at least quarterly data, resulting in additional reporting requirements for IPs.

After some attention to the development of related skills in database management, DQA, analysis, and generation of reports, it is feasible for MEEPP to transfer its database to a prime partner or GOU agency. This should entail a phased process starting with merging of data collection tools.

\section{What has been the effects/impact of MEEPP on the M\&E capacity of PEPFAR- funded IPs?}

Prime partners, including those with good M\&E systems before MEEPP, unanimously reported that MEEPP has helped them organize their data systems through strict deadlines, feedback, and data quality assurance procedures. While MEEPP's data validation meetings were generally viewed as a useful capacity building tool, some prime partners expressed a desire for more focused support. In addition, though it is beyond the mandate of MEEPP to support the M\&E function of IPs directly, some prime partners maintained that the capacity building provided by MEEPP stops at the level of the prime partners and does not sufficiently trickle down to the IPs. This gap is a result of insufficient prime partner M\&E budgets, or because their M\&E department was integrated with service delivery departments, thus receiving limited attention. Reporting from $\mathrm{MOH}$ sites may also be constrained by low capacity among staff.

\section{What has been the effects/impact of the MEEPP project on the national M\&E capacity?}

MEEPP and USG respondents agreed that while capacity building of GOU is not a contractual requirement of MEEPP, MEEPP has to some extent supported GOU M\&E staff 
through ad hoc arrangements. Examples include mapping of ART sites, GIS training, and technical assistance to UAC's database assessment exercise. Respondents from MOH, UAC, and Ministry of Education and Sports reported that they appreciated MEEPP's efforts to facilitate reporting of quality data and involve staff from GOU. Nevertheless, many USG and GOU respondents agreed that the design of MEEPP was not mandated to build the M\&E capacity of GOU.

\section{In summary, what are the lessons that can be learned and what aspects of the project may need change in order to address gaps identified in the current project, namely inadequate national $M \& E$ system's development and capacity building for host-country $M \& E$ and other specialists?}

There is no clear strategy for MEEPP to engage public sector stakeholders. A good M\&E system should be designed to generate data, promote it, and make sure it is accessible to decision makers. Yet MEEPP was not designed to ensure host-country use of its data at the national or district levels. In particular, MEEPP does not interact with GOU at the district level, and there is no system for ensuring that PEPFAR data reaches decision-makers at this level.

Key potential users of MEEPP data are not accessing the data they need. These users include GOU staff at the central and district levels, some staff of IPs, and some USG Contracting Officer Technical Representatives (COTRs). The COTRs' concern is that on the MEEPP database they only access aggregate data, which does not single out the individual IPs that the COTRs are responsible for monitoring. Hence, they request separate reports from the IPs, which may cause unnecessary efforts.

Data from non-PEPFAR civil society organizations not working at health facilities tend to be left out. PEPFAR data includes data on services delivered by PEPFAR IPs using nonUSG funds as indirect contribution to national results. But, for obvious reasons, data from CSOs not funded by the USG are not captured by the PEPFAR database. While these civil society organizations are not the responsibility of MEEPP, such data would provide both GOU and USG with a more comprehensive context in which PEPFAR recipients are operating.

\section{Conclusions}

In light of these findings, the evaluation team offers the following conclusions:

1. The MEEPP design was able to address the reporting needs of PEPFAR, but there is an emerging concern to address the needs of GOU regarding the HIV/AIDS M\&E.

2. In terms of availability and timeliness of output data, MEEPP was implemented as designed. However, the customized reports on the MEEPP website are insufficiently detailed to meet the needs of some stakeholders. 
3. MEEPP has met the expectations of PEPFAR and the prime partners with regard to quality of data; however, several challenges, such as double-reporting, continue to affect data quality.

4. Despite accessibility of the MEEPP website, both in terms of inputting data and obtaining reports, some users still make special data requests to MEEPP.

5. MEEPP has helped prime partners to strengthen their data systems. However some primary data sources (i.e., IPs) require support to strengthen their M\&E capacity.

6. MEEPP does not have an explicit mandate to build the M\&E capacity of GOU agencies. However, it is making special efforts to do so on an ad hoc basis.

7. Aspects of MEEPP that may need change include systematic engagement of public sector stakeholders by promoting and supporting utilization of PEPFAR data, and increased emphasis on evaluation.

\section{Recommendations}

The following recommendations are made in the context of existing USG efforts to support the national HMIS and UAC's performance monitoring and management plan (PMMP). It is also important to note that, for these efforts to yield tangible outcomes, it is necessary for the $\mathrm{MOH}$ to demonstrate leadership on the development of HMIS and for districts to coordinate collection of data from their health facilities and community-based service facilities.

1. In designing a follow-on project to MEEPP, USAID should aim to move from an "emergency mode" and align it with the national systems of data collection and reporting. This would include building capacity of GOU to develop its databases; beginning the process of handing over the MEEPP database to a prime partner or GOU; continuing to support the establishment of a national database that incorporates all HIV and AIDS data in Uganda; harmonizing HMIS and PEPFAR data collection tools and promoting their use; and linking with the roll-out of UAC’s PMMP.

2. USAID should consult with $\mathrm{MOH}, \mathrm{UAC}$, and other host-country users of PEPFAR data to devise ways to address their needs and ensure optimal utilization in policy making and program planning. Ideally, all requests for data and ad hoc analysis should be sent to UAC, and GOU users should receive quarterly reports from UAC. However, in the short-term or transition phase, this should be done by MEEPP while simultaneously building capacity of UAC to assume this responsibility.

3. Realizing that MEEPP has so far concentrated on the monitoring aspects of M\&E, there is the need for USG to work with GOU and other partners to strengthen the current outcome evaluation framework, which largely relies on occasional national surveys as well as epidemiological studies carried out by specific 
research groups. Additionally, each USG agency has plans for end-of-project evaluations. These plans should be linked with the overall national evaluation framework.

4. The follow-up project to MEEPP should support and monitor prime partners to ensure that they provide systematic M\&E support to IPs at peripheral sites. This element could be included in the DQA process that MEEPP provides to prime partners. 


\section{Introduction}

\subsection{Background}

The U.S. President's Emergency Plan for AIDS Relief (PEPFAR) was launched in 2003 to combat global HIV/AIDS. Uganda is one of PEPFAR's 15 focus countries, receiving approximately \$91 million in Fiscal Year (FY) 2004, \$148 million in FY 2005, \$170 million in FY 2006, \$237 million in FY 2007, and \$284 million in FY 2008 to support a comprehensive HIV/AIDS prevention, care, and treatment program. PEPFAR funds more than 80 percent of HIV/AIDS activities in Uganda through implementing partners (IPs), including 70 prime partners (see Appendix 3), which receive direct grants from PEPFAR, and which in turn fund about 1,000 sub-grantee IPs that implement HIV/AIDS services.

Strategic information (SI) is a key component of PEPFAR and is used "to assist host country governments to plan, monitor, and manage a coordinated national response to the HIV/AIDS epidemic; to assist PEPFAR country teams to plan, monitor, and manage USG HIV/AIDS activities in support of the national plan; to provide information to PEPFAR Headquarters for management of PEPFAR; to demonstrate progress of PEPFAR in each annual report to the U.S. Congress; to advocate for continued support and resources of HIV/AIDS prevention, care, and treatment programs; to coordinate efforts with the international donor community."1

In Uganda, SI activities are supported by the Monitoring and Evaluation of the Emergency Plan Progress (MEEPP) project, which has been implemented by Social \& Scientific Systems, Inc. since December 2004. MEEPP has the broad aim of implementing a comprehensive performance management, monitoring, and reporting program for the PEPFAR Country Team in Uganda, which includes the Centers for Disease Control and Prevention (CDC), Department of Defense, Department of State, National Institutes of Health (NIH), Peace Corps, and the United States Agency for International Development (USAID). MEEPP is funded by a \$7,536,180 contract with USAID/Uganda.

Prior to MEEPP, some PEPFAR-funded IPs had not integrated PEPFAR indicators into their performance monitoring plans (PMPs), although the data were available. In other words, there was no linkage between routine reporting and PEPFAR reporting. This was most notable for organizations that were already recipients of other US Government (USG) grants, and were routinely reporting on these, after which they received PEPFAR grants.

The PEPFAR Country Team collects, cleans, and analyze data on PEPFAR-funded activities, and conducts special studies. There are four major results that MEEPP set out to achieve:

1. Improved availability of PEPFAR data

2. Improved quality of PEPFAR data

3. Increased monitoring and evaluation (M\&E) capacity

4. Improved coordinated response

\footnotetext{
${ }^{1}$ The President's Emergency Plan for AIDS Relief. 2009. Next Generation Indicators: Reference Guide. Available at: http://www.pepfar.gov/documents/organization/81097.pdf.
} 
To achieve these results, MEEPP engages in the following activities:

\section{Information collection}

MEEPP collects both qualitative and quantitative information from PEPFAR-funded IPs based on a common understanding of PEPFAR indicators and reporting requirements. MEEPP has developed an online Partner Performance Management Information System, into which IPs enter semi-annual and annual data during two, three-week windows. Quantitative data are entered on site-specific data screens and include outputs such as clients receiving services or reached by education activities, and number of providers trained. Qualitative data is usually presented as a narrative and includes achievements, constraints, and how constraints were overcome. Prime partners have M\&E departments that collate data from their sub-grantee IPs, and then enter the data into databases.

\section{Ongoing data quality assurance}

Data quality assurance (DQA) is provided in several ways for each semi-annual or annual reporting cycle. During data entry, MEEPP supports prime partners using an interactive online approach, reviewing data as they are entered. Secondly, the USG Project Officers or Contracting Officer Technical Representatives (COTRs) review reported data and provide feedback. Thirdly, USG Technical Working Groups (TWGs) and MEEPP use master lists of service outlets to assess and eliminate reporting overlaps. MEEPP also cleans and validates data during and after each reporting period. Finally, USG TWGs and MEEPP staff schedule DQA visits to prime partners and sites, and hold feedback meetings with all prime partners to present the data of that reporting period and to discuss data quality issues.

\section{Data analysis and generation of reports}

After the data have been entered and cleaned, MEEPP staff generates and, with the USG TWGs, reviews reports to assess overlaps and synergies in service delivery. They also map services by type and volume and relate the services to the HIV burden. This analysis helps to show the contribution of USG support to the national response and to identify areas for special studies. The MEEPP database generates aggregate program outputs in the form of semi-annual and annual reports. It also generates reports specific to each USG agency (i.e., USAID, CDC, Department of Defense, Department of State, NIH, and Peace Corps), for each IP, and for each program area [e.g., prevention of mother-to-child transmission (PMTCT) or palliative care]. Other types of reports include district-level aggregate reports by program area, coverage maps for each program area, and master lists of program outputs by prime partners, district, sub-county, and service outlet. In addition, a number of downloads, including graphs, charts, presentations, and comparative trend data, are available for stakeholders, such as USG and selected GOU staff who have access rights to the system. 


\section{Collaboration and coordination}

MEEPP coordinates closely with USG TWGs on HIV/AIDS, particularly with the SI TWG, which supervises and directs MEEPP, approving MEEPP's annual work plan, DQA visits, and special studies before implementation. Finally, the SI Group ascertains if IPs are in compliance with MEEPP procedures and reviews and approves prime partner aggregate reports after they are generated by the MEEPP database.

A variety of groups (clients) use MEEPP's services as shown in Figure 1.

Figure 1 User of MEEPP services (clients)

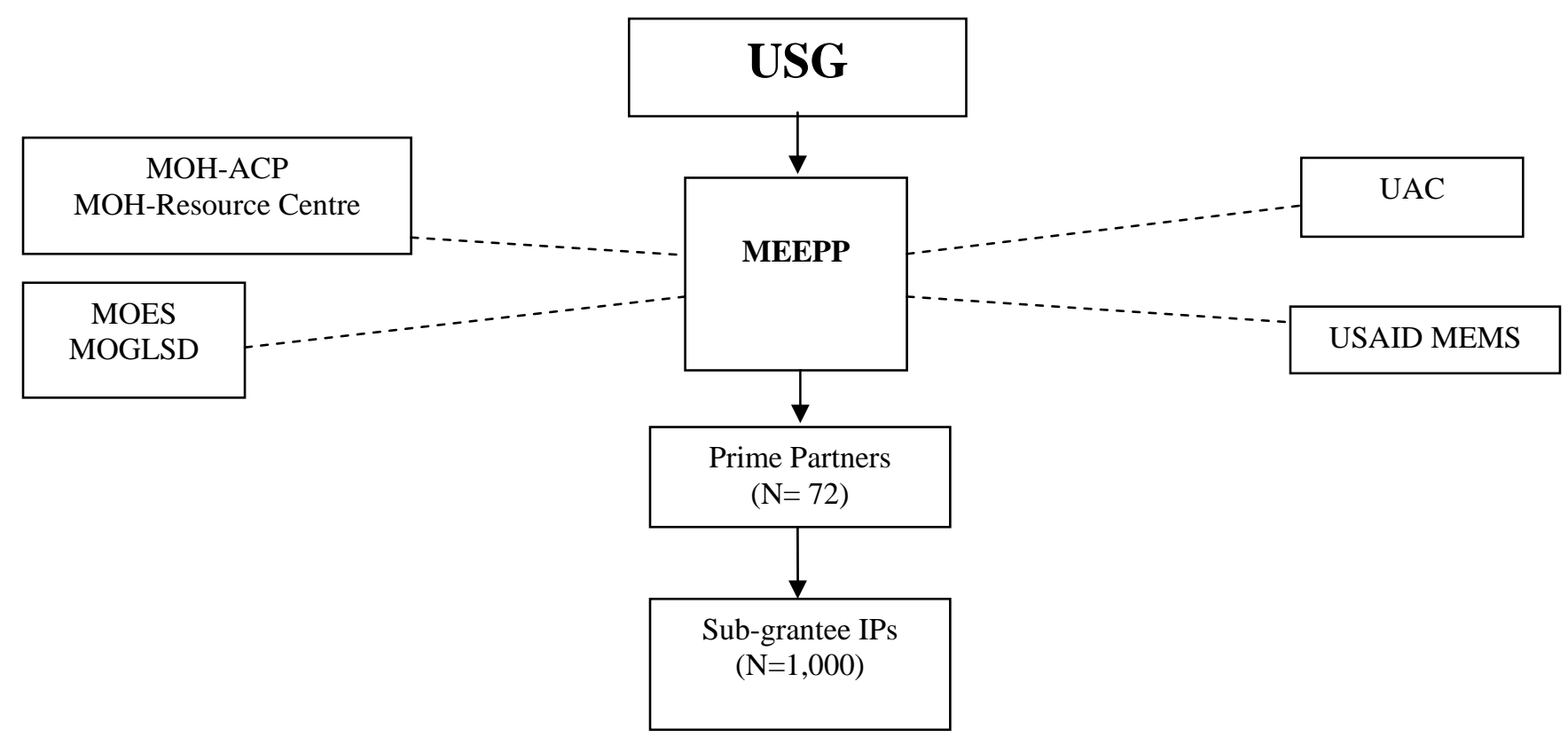

MEEPP has nine Ugandan staff, including the Project Director, two M\&E Specialists, one Management Information Specialist, and Finance and Administrative staff. In addition, MEEPP has one part-time expatriate Senior Advisor.

\subsection{Purpose of Evaluation}

The current MEEPP project is a five year project implemented from December 2004 to December 2009. In August 2009, USAID/Uganda contracted the Population Council to conduct an end-of-project evaluation of MEEPP. USG is designing a follow-up project to MEEPP, and this evaluation was aimed to inform that process. The purpose of the evaluation, as stated in the scope of work, is to critically examine the project to extract the lessons learned, including what did and did not work well, and what needs to be changed in the future with special reference to capacity building of PEPFAR-funded IPs and the national M\&E system. To achieve this, the evaluation sought to answer the following questions: 
1. Overall, was the MEEPP design able to address the reporting needs of PEPFAR and the GOU?

2. Overall, was the MEEPP project implemented as designed?

3. What has been the trend of quality of data reported to the PEPFAR Country Team over the last five years? What has been the role of MEEPP in this regard?

4. What is the status of electronic databases of PEPFAR data with regard to comprehensiveness, compatibility with national systems, ease of use, actual use, and plans or feasibility for handing them over to an appropriate institution once the project is ended?

5. What has been the effects/impact of the MEEPP project on the M\&E capacity of PEPFAR-funded IPs?

6. What has been the effects/impact of the MEEPP project on the national M\&E capacity? (This result was evaluated on the extent to which the project was designed to support the national system.)

7. In summary, what are the lessons that can be learned and what aspects of the project may need change in order to address gaps identified in the current project, namely national M\&E system's development and capacity building for host-country M\&E and other specialists?

It should be noted that MEEPP is only one of many organizations engaged in M\&E work to ensure a coordinated Ugandan response to HIV/AIDS. Other organizations include the $\mathrm{MOH}$ AIDS Control Program and Resource Center and UAC. The evaluation team therefore sought to learn the extent to which MEEPP interacted with these other groups to ensure a coordinated and harmonized M\&E system for the country.

The sections that follow describe the methodology used in this evaluation, the results organized by the seven evaluation questions, conclusion, and recommendations for a followon project. 


\section{Methodology}

\subsection{Data Collection Methods}

The evaluation team began with an extensive literature review to learn about the monitoring and reporting needs of OGAC and to examine the reports submitted to the PEPFAR Country Team. It then conducted in-depth interviews (IDIs) with key technical staff of IPs, GOU agencies, and USG agencies, as well as key informant interviews (KIIs) with executive heads of these agencies. Finally, the team conducted a technical review of the database to assess its status and usability, and examined collection tools and registers at selected service delivery sites. The data were collected between September and November 2009.

\section{Literature review}

The literature review included quarterly reports of MEEPP performance (first quarter of 2005 to third quarter of 2009), as well as explanatory notes that MEEPP produced to accompany each semi-annual and annual report from 2005 to 2008, and reports of aggregate service delivery data compiled according to specific USG funding agencies (CDC, Department of State, NIH, USAID, Peace Corps, and Department of Defense). The evaluation team also reviewed PowerPoint presentations summarizing the MEEPP project, as well as the DQA process and a report detailing the DQA conducted on one of the prime partners (NUMAT). In addition, the team reviewed literature about PEPFAR/Uganda obtained from the PEPFAR website. (These documents are listed in Appendix 1.)

During the literature review, the evaluation team sought to identify achievements and lessons learned from MEEPP's experience from inception to date. The evaluation team assessed MEEPP's products in terms of readability and presentation of information as well as content. Finally, the review considered the quality and utility of special studies and analyses and feedback meetings as reported in the quarterly reports.

\section{Key informant interviews}

The purpose of the KIIs was to evaluate the programmatic aspects of MEEPP. This included: client satisfaction; capacity building; facilitation of a coordinated national reporting system and harmonization; facilitation of sharing of M\&E data, including feedback to districts and service outlets; supporting utilization of data for programmatic and policy decisions; strengths and weaknesses; and recommendations for strengthening. Further, the evaluation team used KIIs and IDIs (described below) to ascertain the views of various users and participants on the quality and utility of analyses, feedback meetings, and special studies. Finally, KIIs examined the ease with which the data on the MEEPP website are accessed, the extent to which these data are put to use, lessons learned, as well as challenges and constraints and how these can be overcome. 
Key informants represented agencies that are beneficiaries of and stakeholders in MEEPP's work. They were identified by the evaluation team with the aim of having at least one person representing each agency shown in Figure 1, excluding the prime partners and their subgrantee IPs. This list was reviewed by the SI TWG, and modifications were made. A total of 23 KIIs were conducted-22 in Kampala and one in Entebbe.

The same interview guidelines were used for the KIIs and the IDIs (Appendix 2). The difference was in the depth and structure of the interviews. The interviewers were experienced researchers and were able to tailor the interviews so that KIIs were less structured and allowed respondents to take their time and focus on a particular aspect of the interview that they deemed most relevant, which the interviewers would follow to a logical concluding point. In addition, some KIIs were intentionally scheduled later in the evaluation process so interviewers could use them to validate or refute emerging themes.

\section{In-depth interviews}

The purpose of the IDIs was to obtain the views of hands-on implementers of M\&E on the user-friendliness of the system developed by MEEPP, awareness and availability of standard operating procedures and data collection tools, supervisory support received, lessons learned, challenges, strengths and weaknesses, and recommendations for strengthening the MEEPP Project.

The IDI respondents represented users along the path of information flow: service providers who complete the MIS forms at sites; those who make site summaries and forward them to prime partners; those who collate summaries at the headquarters of prime partners; those who enter data into the MEEPP database online; technical staff at MEEPP; and those who receive (or are supposed to receive) the consolidated reports from MEEPP. Since more than one person at a site or agency may be involved in these processes (e.g. program staff and M\&E staff), the IDIs sometimes involved more than one respondent at an agency.

Both prime partners and sub-grantee IPs were represented in the IDIs. To guide the selection, a matrix of prime partners (see Appendix 4) was developed by the evaluation team using the following criteria:

- The USG agency supporting the prime partner: USG agencies funding the largest numbers of prime partners (e.g., USAID and CDC, which fund 39 and 23 prime partners, respectively) were allocated a larger share of prime partners from which to conduct IDIs. However, a deliberate effort was made to ensure at least one prime partner of the other USG agencies was visited.

- The program area covered: Using data provided by MEEPP, the evaluation team identified and selected prime partners who contribute a high percentage of output data for a given service area such as HIV testing and counseling or orphans and vulnerable children (OVC).

- Geographical regions: The team sought to ensure diversity of distribution across the four major regions of the country (Northern, Western, Eastern, and Central). 
This matrix was reviewed, modified, and approved by the SI TWG and sent to MEEPP to provide contact information, and where possible, to facilitate appointments.

Prime partner interviews were conducted first — all in Kampala where their headquarters are located, except for one (for which the headquarters are located in Gulu). Following these interviews, the evaluation team selected one sub-grantee IP for each prime partner to be visited. Because of cost and time limitations, the sample of IPs was conveniently selected to suit certain routes of travel for the study team, as follows:

- Eastern route: Bugiri, Mbale

- Northern route: Gulu , Masindi

- Western route: Fort Portal, Mbarara, Masaka, Mubende, Ntungamo,

- Central: Kampala, Kayunga, Luwero, Mpigi, Wakiso

The list of IPs was reviewed and agreed on with the SI TWG, and sent to MEEPP to provide contacts and assistance with making appointments. For each district visited, the team made an effort to visit the District Health Office to obtain its views about MEEPP.

Interviews were conducted with 25 staff representing 18 prime partners and 17 staff representing 14 sub-grantee IPs. ${ }^{2}$ In addition, six interviews were conducted with District Health Offices.

\section{Observation of the data management system}

An experienced database consultant conducted the observation of the data management system. From the literature review, the evaluation team determined that the MEEPP database was well developed and functioning optimally. Thus, the observation of the data management system was largely descriptive, and included a review of the types and processes of inputs and outputs. A checklist (see Appendix 2) was used to follow the pathway from the sites where data are collected by service providers to where information is transferred from the source documents and entered electronically. This path included headquarters offices and $M \& E$ departments of prime partners. In addition to observations, the consultant sought the views of staff regarding the user-friendliness of the tools, the clarity of standard operating procedures, and the level and quality of support received from MEEPP.

Observations of the data management system were carried out at MEEPP offices, two GOU M\&E systems, and two prime partners with corresponding IPs in Eastern and Central regions. These sites were purposively selected based on logistical reasons.

\footnotetext{
${ }^{2}$ For one prime partner, Walter Reed, two IPs were interviewed while for Peace Corps Mubende, a peripheral IP, no corresponding prime partner interviewed. For logistical reasons, no IPs were interviewed for AFFORD, CSF, Mildmay, and PREFA.
} 


\subsection{Data Analysis and Management}

The analytical framework for this evaluation was based on two basic principles: a) the purpose of the evaluation and the seven evaluation questions as stated scope of work; and b) the mandate of MEEPP as stated in the four major results. The evaluation team used the literature review to generate tentative findings for each evaluation question. Qualitative data from IDIs, KIIs, and observations of the data management system were then used to either validate or invalidate these tentative findings. Data collection and analysis ran concurrently. The evaluation team held de-briefing meetings every two days to identify main emerging themes. Important findings requiring further inquiry were pursued on subsequent days.

Lines of inquiry that were duplicating existing information were dropped from subsequent interviews. Themes that appeared well-established from initial data were written up as part of the preliminary evaluation report (but could be changed if they were disputed by later data). Emerging themes were shared among the evaluation team, the USAID staff, the Country Team, and finally with MEEPP. These sharing sessions enabled the various stakeholders to seek clarifications, add more data, add more lines of inquiry, or dispute tentative conclusions. In some instances, the evaluation team went back to some respondents after the sessions to ask further questions or seek clarifications.

Through this process, the team developed a list of recommendations for the MEEPP followon project. These recommendations were extensively discussed with the COTRs for MEEPP.

All interviews were recorded on audio tapes and transcribed into Microsoft Word documents. The audio tapes and the printed transcripts were stored under lock and key. Notes from sharing sessions and de-briefing sessions were taken by hand and typed into Microsoft Word. All Word documents were then read and coded according to themes, which were developed by the evaluation team when discussing initial interviews and refined as more data became available. The findings were then organized along the seven evaluation questions.

\subsection{Ethical Considerations}

This evaluation methodology was reviewed internally within the Population Council and exempted from the full Institutional Review Board review on the grounds that it is not a clinical study, does not involve vulnerable populations, confidential medical information, or physically invasive procedures, and would not expose participants to health, legal, or psychological risks. To ensure that participants' responses remain confidential, respondents were interviewed individually in the privacy of their offices; all transcripts and audio tapes were kept under lock and key in the Council's data room, and personal identifiers have been removed when respondents are quoted in this report and in presentations of the data.

\subsection{Limitations}

The scope of this study was limited to MEEPP and thus the results it was contracted to achieve. However, as noted above, MEEPP interacts with several other M\&E systems, such 
as the GOU M\&E systems, which are intended to coordinate the M\&E efforts of donors such as PEPFAR. A comprehensive assessment of MEEPP's role in collaboration, coordination, and harmonization would have to include these other M\&E systems. Thus, the conclusions of this evaluation do not reflect the strengths and weaknesses of these systems and how they could have affected the success of MEEPP. Another limitation of the evaluation is the absence of a baseline assessment of the HIV M\&E system in Uganda before the implementation of PEPFAR-funded activities. As such, it is difficult to discern the effects of PEPFAR's broader focus on a coordinated USG response from those of MEEPP's efforts to foster collaboration among USG agencies. Further, the selection of prime partners included in the evaluation intentionally favored the prime partners reporting the largest absolute numbers served in a given program area. This was because they were considered to have the largest influence on the data reported. However, it inevitably biased the findings towards the experiences of the larger organizations at the expense of the smaller ones. Finally, given cost and time limitations, the sample of IPs was conveniently selected to suit travel routes of the study team, which could have introduced a bias by excluding more remote IPs. 


\section{Results}

The following section presents the results of the evaluation organized by the seven evaluation questions.

\subsection{Overall, was the MEEPP design able to address the M\&E needs of PEPFAR and GOU?}

If you wanted data about different partners in the country, about what they doing, where they are working, the place to go is MEEPP.

-Prime partner staff person

Respondents consistently reported that the MEEPP design was able to meet the reporting needs of PEPFAR. As an emergency program, PEPFAR requires timely and accurate reporting of its outputs to support ongoing funding. MEEPP has been able to meet this need, designing reports based on PEPFAR indicators and meeting Country Team's deadlines. PEPFAR indicators are subject to change, sometimes on short notice, and MEEPP has generally been able to reflect these changes in its reports. However, such changes also cause considerable stress for some IPs, which struggle to meet deadlines, report on some indicators, and enter data with proper cleaning or verification. In some cases IPs miss reporting periods altogether. It should be noted that the issue of changing indicators is a Country Team issue and not within the control of MEEPP. On the other hand, some respondents reported that strict deadlines help the IPs to streamline and organize their work.

USG respondents acknowledged that it was never the intention of USG to support the M\&E needs of GOU through MEEPP. At the same time, in commissioning this evaluation, the USG team sought to determine ways to address gaps identified in the current project, namely, national M\&E system's development and capacity building for host-country M\&E and other specialists. Thus, the evaluation team specifically investigated the extent to which MEEPP was meeting the M\&E needs of GOU.

USG respondents underscored that MEEPP was designed by PEPFAR for emergency purposes of providing PEPFAR data in order to guide the emergency plan and hence there was limited time for local consultations to take into consideration the role of GOU. Instead the USG procured other means of providing technical assistance to GOU to strengthen its M\&E system, including the AIDS Capacity Enhancement project to support database development for the UAC, a contract with the Population Council to provide technical assistance to UAC to roll out its PMMP, and strengthening the MOH's HMIS system through support to the Resource Centre.

Nonetheless, GOU respondents widely maintained that MEEPP is not meeting GOU expectations and needs. These expectations could be a product of two factors. First, the vast majority of HIV/AIDS programming in Uganda is funded by the USG, and MEEPP collects a similar proportion of output data from HIV/AIDS services in the country. Secondly, MEEPP is considered the most reliable source of service delivery data in the country. Thus, the 
volume and quality of data collected by MEEPP may have fostered the perception that MEEPP has overtaken the HIV/AIDS M\&E function of GOU. As a result, several respondents felt that MEEPP should have been embedded in a key GOU structure such as the Resource Center or UAC.

\subsection{Overall, Was MEEPP Implemented as Designed?}

\section{Providing data on PEPFAR funded activities as required by the Country Team}

MEEPP was designed to provide the Country Team with timely, high quality output data from all sites funded by PEPFAR in Uganda. It was the unanimous view of respondents that MEEPP was well implemented as designed. OGAC requires each PEPFAR-funded Country to prepare two reports per year: a semi-annual report, covering the period 1 October to 31 March, and an annual report, covering 1 October to 30 September. Since its inception, MEEPP has consistently produced these reports on time, delivering the draft semi-annual reports to the Country Team in April and the annual reports in October. These reports are broken down by geographical region, type of service, type of IP, and reporting period. The database also provides a variety of standard reports focusing on program-level indicator totals. MEEPP submits reports by e-mail and thereafter sends hard copies to the Country Team and prime partners. The evaluation team found that the reports were readily available and current.

However, this design is not without consequences. Because the deadlines are set by OGAC and are non-negotiable, meeting them places a burden on all that are involved in the process. Indeed, MEEPP and IP respondents reported that prime partners suspend their own M\&Erelated work during the three weeks of data entry. Prime partners also spend considerable time extracting data from IP reports.

In addition, the level of sophistication varies at the sites reporting data. The primary data sources are the service delivery sites of IPs, many of which are based in the districts at $\mathrm{MOH}$ health facilities or non-governmental organization settings. For example, Mildmay, a prime partner, has provided computers to all its sites for data entry. However, the sites do not have internet connections to send the data. Instead, M\&E staff from headquarters must travel to the sites to obtain the data. On the other hand, Joint Clinical Research Center sites send data by e-mail, and the AIDS Information Centre enters data in Epi Info, an epidemiological data capture program, sometimes hiring consultants to analyze the data locally.

Quality assurance of data entered into the database is another key component of MEEPP. Respondents reported that MEEPP provides sufficient supervisory support during and after the data entry period to ensure both the quality and timeliness of the data. The data quality assurance is provided either on demand by the prime partners, or as feedback on the data entered by the prime partners. 


\section{Presenting data on PEPFAR-funded activities to inform programming decisions}

Data generated by MEEPP are intended to be used to strengthen PEPFAR programming in Uganda. MEEPP cites several ways the data it generates are put to use. On a strategic planning level, data are used to assess overall progress achieved by PEPFAR, to compare this progress to strategic country targets as well as specific progress registered in each program area, and to facilitate the Country Operational Planning (COP) process. Specifically, MEEPP provides the data used by the TWGs to set annual targets for the new COP. In addition, TWG members request and receive ad hoc analyses on a variety of programmatic issues. These requests frequently included additional analyses to be used in program planning, such as data by specific age groups, geographical regions, and program areas.

At the program implementation level, the data are used to assess progress of and provide feedback to individual IPs to improve their performance, and to encourage partners to network and seek synergies. Review of outputs also helps prime partners to assess the strengths and weaknesses of their M\&E systems, and to use their own databases for strategic planning. MEEPP provides feedback to the prime partners on the data they reported and on comparisons with other prime partners. This feedback covers trend analysis, the extent to which national targets are being met, and geographical coverage. Prime partners reported that this kind of feedback was vital for planning their activities. For example, Mildmay changed its HIV testing strategy when the data revealed that it was mainly reaching low risk populations. Similarly, the AIDS Information Centre determined that it needed to recruit additional staff to increase coverage and meet its targets. On the other hand, some prime partners expressed the view that, in general, routine feedback usually focuses on the quality of data reported rather than on the program implications of the data.

Host country policy makers also report using data on PEPFAR-funded activities, although not through a structured routine feedback process such as the one MEEPP conducts for the TWGs and prime partners. USG invites officials from GOU and the United Nations agencies to attend data dissemination meetings. For example, a dissemination meeting on the semiannual report of 2008 included staff from UAC, MOH, MOGLSD, the World Health Organization, and UNAIDS. During this meeting PEPFAR contributions and trends in performance from 2005 to 2008 were reviewed. MEEPP also reported that, with USG, it organized and facilitated consultation meetings with UAC, MOH, and MGLSD to validate the data from this report. Finally, MEEPP quarterly reports cite several examples of GOU utilizing data on PEPFAR-funded activities: for its Global Fund application in 2007, the HIV/AIDS National Strategic Plan in 2008, and for compiling a UNAIDS report of the national response in 2009. This information was corroborated by some GOU respondents, who reported that they receive service delivery data on PEPFAR-funded activities that helps them in program planning.

What I know is that, PEPFAR helped us to improve our capacity in service delivery. MEEPP gave us an opportunity to look at data from the source. I also got a report on universal access (to antiretrovirals), that report had support from MEEPP. 


\section{Fostering collaboration, coordination, and harmonization}

USG staff reported that MEEPP has enhanced collaboration between the agencies comprising the TWGs, between the TWGs and IPs, and between the Country Team and the GOU. Arguably, it may be difficult to tease out the impact of PEPFAR's efforts at coordination from those of MEEPP. However, some USG respondents singled out MEEPP as being responsible.

I give MEEPP all the credit because it has brought CDC and USAID together. Through $M E E P P$ 's work and interaction, it has tried to bridge the gap between these two organizations.

-USG staff person

On harmonization, [MEEPP] has played a big role; they are better resourced, able to follow up on information. Sharing information with us means harmonization and also data audits-all are towards harmonization. However, the coordination if any has been for PEPFAR partners and collaboration is mainly with PEPFAR partners, but also with $\mathrm{MOH}$ especially on issues of figures.

$-\mathrm{MOH}$ staff person

Prime partners also reported that the feedback meetings and the review of coverage data demonstrating duplication of service delivery have enhanced coordination and collaboration.

\subsection{What Has Been the Trend of Quality of Data Reported to OGAC Over the Last Five Years? What Has Been the Role of MEEPP in This Regard?}

USG respondents indicated that they were satisfied with the quality and timeliness of data reported to OGAC over the last five years, giving credit to MEEPP. MEEPP respondents, in turn, noted that data quality has also improved with the clarity of the indicators. Often when OGAC sends new PEPFAR indicators to the country, prime partners have different interpretations about the numerators and denominators that feed into that indicator and how that data are to be collected at the site level. MEEPP prevents this confusion by holding meetings of all prime partners to reach a clear common understanding of the indicators, thus resulting in data that have the same meaning across prime partners.

MEEPP staff also maintain that MEEPP provides the most accurate HIV/AIDS M\&E data to the USG and other national partners, such as Joint Clinical Research Center, UAC, and $\mathrm{MOH}$. This is corroborated by both USG staff and GOU staff:

MEEPP, collects, cleans and reports PEPFAR results every year during which the semi and annual reports are made. It has also done a good job of using the data to improve the program. 
The information most of the times would be accurate and complete as it comes to MEEPP than HMIS, e.g., data on HIV counseling.

-GOU staff person

MEEPP has had particular success integrating PEPFAR indicators with the other USG indicators, which USG-funded partners had previously struggled to reconcile. This has resulted in unified reporting on USG grants.

MEEPP has brought some order regarding reporting systems.

-USG respondent

MEEPP has also strengthened the capacity of IPs to conduct DQA by fostering a common understanding of the definitions of indicators. As mentioned above, whenever OGAC sends a new PEPFAR indicator, USG convenes the prime partners to ensure they have a consensus on what the indicator means and how the data will be collected. USG and MEEPP have trained IPs to conduct DQA on the web during and after data entry. Further, web-based reporting made it easy for the IPs to input data with minimal errors.

According to most prime partners, a specific area where MEEPP significantly improved data quality was the reduction of double reporting of clients receiving services. Double reporting can occur if one client receives a service, such as HIV testing and counseling, twice within the reporting period from different IPs in the same health facility. The efforts by MEEPP, USG agencies and prime partners to promote the use of unique identification numbers for each client have been particularly effective. However, considering that there are no national photo identity cards in Uganda, the use of a unique identification numbers has its limitations. A second MEEPP effort to reduce double-counting is the feedback meetings of all prime partners to review outputs reported and data submitted. During these meetings, outputs are compared for specific program areas where two IPs are reporting from the same facility. If MEEPP identifies overlaps in the data reported by the two IPs, the data are verified by bringing the IPs together to reach consensus. A third approach is that MEEPP's documentation of services delivered is broken down by district, county, sub-county and site, with a master list showing the primary source in terms of site and sub-county. Where more than one IP operates in the same location offering the same service, the IP reporting the largest amount of services is taken as the primary reporting IP, and the data of the other IPs are included in the data of this index IP. A fourth approach to reduce double- or overcounting is that outreach-specific data, which are reported at the parish level, are verified with the parish populations. In this case if an IP reports reaching a number which exceeds the total parish population, MEEPP highlights this error to the IP and it is corrected. Finally, data quality assessment visits to selected sites deal with the issue of double-counting at the IP level.

Another way in which MEEPP strives to improve data quality is through comparisons with historical trends in performance. USG and MEEPP hold meetings with prime partners to clarify issues and address queries.

However, respondents also expressed concerns about the quality of data produced by MEEPP. Double-counting, particularly when multiple service delivery organizations provide 
the same service at the same health facility, remains a concern, despite the measures MEEPP has implemented to avoid it.

You find many programs in the same facility, e.g., a health centre. Yet there are many other areas without the same services which are not reached. Actually, an easy solution to the problem of double counting would be to reduce double implementation or duplication by partners.

-Prime Partner staff person

Other respondents indicated that stringent reporting deadlines undermine data quality. This can be especially problematic if prime partners enter data on the website before verifying and validating them with source IPs. The introduction of new indicators late in the cycle may also affect quality, as some sites are unable to revise their data using the new indicators, and their data gets left out altogether. It should be noted that the introduction of new indicators and the strict deadlines are issues dictated by OGAC and are beyond the control of MEEPP. A final issue is the accuracy of service delivery statistics for prevention interventions, especially those involving mass communications. While facility-based data sources (e.g., registers) are easier to validate, HIV/AIDS prevention data are mainly based on estimates of the numbers reached by mass media and may therefore be less accurate than treatment data.

\subsection{What is the Status of Electronic Databases, With Regard to: Comprehensiveness, Inter-Operability With National Systems, Ease of Use, Actual Use, and Plans or Feasibility For Handing Over to An Appropriate Institution Once the MEEPP Project is Ended?}

\section{Comprehensiveness}

The technology for the MEEPP database was initially based on Microsoft Excel. Recently, MEEPP changed to the superior SQL Server 2005 and ASP.NET web-based technology. This is because web pages developed in ASP.net technology are not affected by the type of internet browser the website visitor is using. MEEPP uses Microsoft applications (Word and Excel) for reporting. It also uses ArcView for maps, analyses, and generation of reports, which is an easy-to-use and flexible program. For example, ArcView can generate reports by region, district, county, and sub-county, and summaries can be exported to Word and Excel. The MEEPP system complies with the dynamic PEPFAR reporting requirements. Further, MEEPP upgrades its system to comply with relevant users such as USG agencies.

The database and web server are housed at the MEEPP office in Uganda, with an off-site backup in the U.S. The system has a broadband connectivity that is guaranteed by two internet providers in case one fails. The power system also has a back-up in case of surges.

The electronic database is accessed on www.meepp.or.ug. Prime partners have passwords to log-in, and they access and report directly on the web. Prime partners receive data in various 
formats from their sub-grantee IPs, though usually in Microsoft Excel. Comprehensive data is sent by IPs to prime partners as Excel attachments. The M\&E staff of prime partners extracts relevant data for input into the MEEPP database. These data are uploaded into the database manually, which is time-consuming. A major issue is slow internet connections caused by small bandwidth and overloading by many people entering data at the same time. This depends on the physical location of the prime partners and the internet service provider. If the prime partner is located in an area with many internet users or if the service provider provides a small bandwidth, then the internet connections are very slow. Hence, some prime partners work at night and/or go to the MEEPP offices to enter the data.

\section{Inter-operability with national systems and other USG M\&E systems}

With regard to inter-operability of data-based systems, the MEEPP system is adaptable to GOU and other stakeholder needs since many of the indicators are similar or relate to national indicators. However, the HMIS is not compatible with MEEPP. HMIS is Microsoft Access-based, while the MEEPP database is web-based. Further, the UAC currently does not have a functional database; a web-enabled database was under development through the USAID-funded AIDS Capacity Enhancement project, but the project ended before the database was completed.

Respondents were asked about the extent to which they felt the M\&E system developed by MEEPP was linked with other USG team systems, especially those of the Civil Society Fund and USAID/Uganda's MEMS system. Respondents indicated that while MEEPP links with these systems in some way, efforts to draw boundaries or to link MEEPP with these two systems are not systematic and that these two systems are still evolving.

Civil Society Fund is one of the largest contributors of data on PEPFAR-funded activities. Civil Society Fund is also currently developing its own M\&E system. However, many of the civil society organizations struggle to meet MEEPP standards, despite Civil Society Fund training on M\&E.

There are fragile sub grantees. They send in their reports late. There are also problems and inconsistencies in their data. We have to call almost every one of them to sort out these inconsistencies and issues related to following guidelines.

-Prime partner staff person

There also appears to be confusion among some IPs about the role of MEMS and its relationship to MEEPP.

...there is no connection between MEMS and MEEPP projects. There has been a change and MEMS has been given a mandate to give assistance to PEPFAR partners in respect to developing PMPs. The Mission has decided that we should support the IPs to develop PMPs based on USAID standards. Some PEPFAR partners have PMPs but some simply have a list of indicators. The MEEPP database formats focus on the facility level. 
However, some IP respondents identify MEMS with evaluation and analysis of service delivery data, with MEEPP focused on monitoring of service delivery. Others view MEMS as responsible for the M\&E of USAID-funded organizations only, while MEEPP covers all organizations funded through PEPFAR.

\section{Ease of use and actual use}

Prime partners frequently reported that the MEEPP database was easy to use:

...the web-based reporting system... makes reporting easy, fast, and accurate.

Their system is user friendly and it cannot be manipulated... We now generate reliable data because of their guidance.

In addition to MEEPP and prime partner staff, a number of other stakeholders have accounts with passwords to access to the database online, but with varying rights. The USG COTRs or Project Officers and some selected GOU officials have "read only" access. All users have access to aggregate data and downloads.

MEEPP staff, however, complained that some people do not use the accounts. Instead, they telephone MEEPP and request data after stating that they have forgotten their password and/or username. In addition, some prime partners reported that their COTRs cannot access their specific data in the MEEPP database.

...we can only discuss the narrative report with our focal person in CDC. But that person has no access rights to the report. As an IP, we report to CDC with an elaborate report every six months. Our report becomes part of the report for CDC on country programming.

-Prime partner staff person

This view was also expressed by at least one COTR, who noted that: "The database needs to be more user-friendly for COTRs. I need to see whether my IPs are meeting their targets.”

Thus, it appears that while MEEPP provides passwords to COTRs, their access is limited to aggregate data. As a result, prime partners separately report the same data to their COTRs.

It was further expressed that procedures for obtaining deeper analysis of the data are sometimes cumbersome.

There is limited use of MEEPP data because it is given to so few people. In case somebody is to help you with the work/delegation, you have to go through a long procedure: you need to talk to the Chief of Party, then you inform the MEEPP officials 
who have to give the delegated person permission to have a password to use the data. This process is really long and tiresome.

-Prime partner staff person

MEEPP has also provided passwords to some key GOU personnel in MOH and UAC. However, these staff often need data analyzed by different age groups than those provided in the MEEPP database. They may also need data by specific districts, which MEEPP does not readily provide in its analysis. In these instances, they are encouraged to write to the Project Director of MEEPP to obtain that analysis, which some GOU respondents reported as prohibitive and time-consuming.

MEEPP confirmed that there have been numerous requests for data and ad hoc analyses from a variety of consumers including GOU, USG, and independent researchers. However both MEEPP and senior USG respondents have stated that letting individuals carry out their own analyses would jam the system and might put the database at risk of both intentional and unintentional contamination. MEEPP staff indicated that when requests are received in an orderly fashion, preferably in written form, their response is usually instant, especially if the data are readily available. However, requests that require contacting sites for additional data may take longer. In addition, if the request came during the three-week period prior to the reporting deadline, a delay of up to two weeks is possible to meet such a request.

\section{Feasibility of technology transfer}

The evaluation team believes that, after some attention to the development of related skills in database management, DQA, analysis, and generation of reports, it is feasible for MEEPP to transfer its database to a prime partner and GOU agency. This process will be facilitated by the fact that MEEPP has good documentation of the database user instructions. The evaluation team recommends that MEEPP transfer the database and its related systems to a GOU institution once the project is terminated. However, respondents underscored that this should entail a phased process starting with merging of data collection tools. USG staff concurs, with one individual noting that: "The ideal situation is that the sites should use national tools and make copies for MOH and copies for MEEPP.”

Another prerequisite for technology transfer is the need to harmonize indicators. Some effort has already been undertaken to harmonize several indicators between PEPFAR and HMIS, and so far seven indicators have been harmonized. USG respondents noted that while PEPFAR indicators are revised frequently, HMIS indicators are revised once in every five years. They also noted that both PEPFAR and HMIS have indicators that do not overlap and hence, in order to continue with harmonization, there is need to identify those indicators that are shared. A related issue is that different USG agencies require more data than are collected by the PEPFAR indicators.

The harmonization of indicators should lead to the development of a single data collection tool for use by both HMIS and PEPFAR at service delivery sites. Indeed, a number of prime partners are already using the $\mathrm{MOH}$ data collation tools to extract data from the registers at the service delivery sites. These forms are completed and copies are sent to the prime partners 
and to the District Health Office, and a copy is left with the sites. Other prime partners, however, have not completely harmonized their data collection tools with those of the MOH. Further, HMIS and OGAC reporting operate on different schedules (e.g., quarterly versus semi-annually and annually). Hence, service delivery sites use different formats to send reports to different stakeholders such as MOH and USG agencies. This results in additional work for the M\&E staff as well as duplication of effort.

\subsection{What Has Been the Effects/Impact of MEEPP on the Reporting Capacity of PEPFAR-Funded IPs?}

Prime partners, including those with good M\&E systems before MEEPP, unanimously reported that MEEPP has helped them organize their data systems through strict deadlines, feedback, and data quality assurance procedures. MEEPP has been of particular value to those organizations expanding rapidly under PEPFAR, with concomitant demands on their M\&E departments.

Before PEPFAR we were only in six sites. But with PEPFAR support we are now in 52 sites. We had an M\&E system but it was not up to the standards that USAID wanted so we had to improve on it.

-Prime partner staff person

Web-based reporting has helped to demystify IT to some staff of prime partners who were reluctant to fully apply it. MEEPP is also credited more generally with creating positive attitudes towards M\&E among the staff of some prime partners.

MEEPP has made $M \& E$ enjoyable. Some $M \& E$ components, e.g. bio aspects, were very difficult for us social scientists. But now we can use the M\&E tools very well.

-Prime partner staff person

While MEEPP's data validation meetings were generally viewed as a useful capacity building tool, some prime partners expressed a desire for more focused support:

MEEPP has been inviting all the partners at the same time. You find that the place is crowded, and I wonder whether all the partners benefit at the same rate. Therefore, a fewer manageable number of partners should meet at a particular time for better results.

-Prime partner staff person

It is beyond the mandate of MEEPP to ensure that the IPs have the capacity to report high quality and timely data to prime partners. Instead, MEEPP provides support to prime partners, which in turn support the IPs. Some prime partners have reported that this "trickle down” approach has been successful:

The monitoring officers pass on this knowledge that they have acquired as they do support supervision to the implementing sites. We carry out trainings (especially to 
data officers) when a need is identified. In case there is a feedback from MEEPP, the message is passed on to the different region who pass on to the staff concerned.

-Prime partner staff person

One prime partner reported that MEEPP even provides training to its IP staff upon request, and that whenever it hires new staff, it calls upon MEEPP to train them in M\&E.

However, other prime partners maintained that the capacity strengthening provided by MEEPP stops at the level of the prime partners and does not sufficiently trickle down to the IPs:

I have not gotten any training personally. There has been nothing in terms of systems development. The M\&E officials at the head office have not also helped us much. -IP staff person

Respondents from MEEPP and USG emphasized that it is the role of prime partners to have a strong M\&E system within their sub-grantees to ensure high quality and timely data. When asked about this issue, most prime partner respondents affirmed that they have budgets and work plans for M\&E. However, in some cases the budgets were insufficient or the M\&E department was integrated in service delivery departments, and thus received limited attention.

Further, a respondent from MOH expressed concern about the quality of data on PEPFARfunded activities at $\mathrm{MOH}$ sites where there are no staff trained in $\mathrm{M} \& \mathrm{E}$, and the fact that some local government sites, that have grants from PEPFAR, do not report regularly.

\subsection{What Has Been the Effects/Impact of the MEEPP Project on the National M\&E Capacity? (This Result Was Evaluated Based on the Extent to Which the Project Was Designed to Support the National System)}

The USG requires MEEPP to link with the M\&E efforts of GOU, but has not provided for a structured relationship between MEEPP and GOU through which this link could be realized. In its first quarter of 2005 report, which was also the Inception Report, MEEPP reiterates that: "Capacity building is an important focus of the MEEPP project, and it is targeted to contribute to strengthening knowledge and systems for a sound, sustainable national HIV/AIDS M\&E system.” In the same document, MEEPP indicates that its role is: "...facilitating harmonization and aggregation of data, coordination with the Government of Uganda, and avoiding duplication of effort.”According to MEEPP and USG respondents, MEEPP has to some extent provided support to GOU M\&E staff through ad hoc arrangement in spite of the fact that capacity building of GOU is not a contractual requirement of MEEPP.

MEEPP does not have a contract with MOH to build capacity of government HMIS. In fact they have gone out of their way to help facility reconciliation. MEEPP is a contractor and serves employer's interests. It has done a good job of having a mirror 
system in facility data that MEEPP shows $\mathrm{MOH}$ and helps $\mathrm{MOH}$ to see problems with data. This is not a parallel system but a mirror system.

-USG staff person

For example, in its Inception Report, MEEPP recognized that host country institutions required capacity building, specifically in the area of mapping of ART sites. Indeed, MEEPP, working in collaboration with GOU, did carry out this mapping in early 2005. In addition, MEEPP provided GIS training to MOH staff in 2005 and technical assistance to UAC's database assessment exercise, which was part of the National Strategic Plan development activities, in 2006. Respondents from MOH, UAC, and Ministry of Education and Sports reported that they appreciated MEEPP's efforts to facilitate reporting of quality data and involve staff from GOU. Indeed, based on several data validation visits, one $\mathrm{MOH}$ respondent reported that "MEEPP produced uncontestable data."

Nevertheless, many USG and non-USG respondents agree the MEEPP design paid insufficient consideration to how best to build M\&E capacity in GOU structures. Moreover, GOU had its own expectation that MEEPP would provide capacity building to its M\&E functions. UAC expressed this view as early as 2005, during a SI meeting convened by USG.

There is also a view that MEEPP has affected the functionality of the M\&E capacity of GOU with regard to HIV/AIDS service delivery statistics. GOU respondents, especially those from MOH/AIDS Control Program and UAC, have strongly argued that MEEPP should have been embedded in a government institution to foster synergy between MEEPP and MOH and to ensure good M\&E data collection and reporting. This synergy, however, is currently minimal and ad hoc. USG staff report that GOU is not carrying out its mandate sufficiently:

MOH has failed to coordinate the HIV data. Yet MEEPP is functional and seen to have taken away the responsibility of the MOH concerning HIV data. As a result, $\mathrm{MOH}$ blames MEEPP for not working with it somehow.

\subsection{In Summary, What are the Lessons that Can Be Learned, and What Aspects of the Project May Need Change in Order to Address Gaps Identified in the Current Project, Namely National M\&E System's Development and Capacity Building for Host-Country M\&E and Other Specialists?}

\section{There is no clear strategy for engagement of public sector stakeholders.}

A good M\&E system should generate data, promote it, and make sure it is accessible to policy makers and program managers to utilize in their decisions. Yet MEEPP was not designed with a systematic plan to engage agencies and institutions that supervise service delivery — such as the District Health Office, $\mathrm{MOH}$, and UAC — and to ensure that they are able to access and use data on PEPFAR-funded activities. In particular, MEEPP does not interact with GOU at the district level, and there is no system for ensuring that PEPFAR data reaches decision-makers at this level. Indeed, during a debriefing with the USG team it was 
stated that: "Ideally each IP is required to send reports to the districts." However, only some prime partners share data with the District Health Office.

\section{Key potential users of data on PEPFAR-funded activities are not accessing the data they need from the database.}

These users include GOU staff at the central and district levels, some staff of IPs, and some USG COTRs. The COTRs' concern is that the MEEPP database provides aggregate data, which does not single out the individual IPs that the COTRs are responsible for monitoring. Hence, they request separate reports from the IPs, which may require unnecessary efforts.

\section{Data from non-PEPFAR-supported civil society organizations not working at health facilities tends to be excluded from PEPFAR reports.}

At present, non-PEPFAR-supported CSOs are reporting to neither MOH nor USG. While these civil society organizations are not the responsibility of MEEPP, such data would provide both GOU and USG with a more comprehensive context in which PEPFAR recipients are operating.

\section{MEEPP puts little emphasis on evaluation.}

MEEPP focuses on trend analyses of service delivery statistics as well as geographical coverage. As a result, PEPFAR performance in Uganda is being judged solely in terms of these outputs. Evaluative studies are required to assess quality, efficiency, client satisfaction or impact.

The data that MEEPP reports satisfies PEPFAR because that is what MEEPP was contracted to do. But this data is not very useful to us. It is just basic data. [We] need more qualitative data than what MEEPP provides.

-USG staff person

We need a formal evaluation for the program focusing mainly on quality, not numbers. We can tell the districts that we are doing well. But what about the general performance?

-Prime partner staff person

During a debriefing meeting with the evaluation team, USAID staff agreed that there is a gap with regard to extra data analysis and evaluation, but they were quick to stress that MEEPP should not be misunderstood to be a research organization that analyzes and interprets data. Prime partners confirm this limited role: 
The evaluation function is so limited and I think it is periodic...But I think it is not their mandate to do the evaluation. It is MEMS function, not MEEPP's function. MEEPP is basically to provide information/ data for these evaluation studies.

MEEPP has, nevertheless, carried out a number of special studies. According to its quarterly reports, these include: mapping the service delivery points of ART; validating indirect USG support in CT, PMTCT, and OVC; a needs assessment for laboratory data management in 12 districts; and several studies examining tracking of and accounting for clients. Thus, it appears that MEEPP has limited itself to special studies that support its mandate of providing accurate monitoring rather than evaluating outcomes. 


\section{Conclusions}

This section highlights key conclusions of this evaluation following the structure of the evaluation questions.

\section{Was the MEEPP Design Able to Address the Reporting Needs of PEPFAR and GOU?}

The MEEPP design was able to address the reporting needs of PEPFAR, specifically, to collect data for reports to OGAC. However, capacity building of GOU's key M\&E institutions was not included in the MEEPP design. In retrospect, GOU would have preferred MEEPP to be institutionalized within a GOU agency. In addition, GOU had high but unrealized expectations of synergy between MEEPP \& HMIS.

\section{Was MEEPP Implemented as Designed?}

MEEPP was implemented as designed in terms of availability of timely output data. Reporting deadlines are met, facilitated by web-based access to the database by prime partners. Prime partners can easily enter their data, and MEEPP provides excellent DQA during and after the data entry period. Reports are current, readily available, and accessible to staff of GOU, USG, and IPs on the MEEPP website. However, these customized reports do not provide sufficient details for some stakeholders to use for decision making and planning. MEEPP provides further analyses of data upon request, but the procedure for requesting these special analyses is considered cumbersome.

\section{What Has Been the Trend of Quality of Data Reported to OGAC?}

MEEPP has met the expectations of the Country Team and the IPs with regard to quality of data. Data on PEPFAR-funded activities are considered a credible, alternative source of information for government institutions and other agencies. However, despite MEEPP's efforts, double-reporting remains an issue. While not the responsibility of MEEPP, inadequate attention to capacity building of staff at the primary data sources and sudden revisions in PEPFAR indicators also compromise data quality.

\section{What Is the Status of Electronic Databases for PEPFAR Data?}

It is easy to upload data and access reports in the MEEPP database. However, during peak periods, data entry can be slowed by poor internet connections and power outages. It is feasible to hand over the MEEPP database to an appropriate institution once the project has ended. This handover requires transfer of skills through training and a phased approach that 
should start with the harmonization of indicators with HMIS and the use of a single data collation tool at service delivery sites.

\section{What Has Been the Impact on the M\&E Capacity of PEPFAR-funded IPs?}

MEEPP supports one level of PEPFAR IPs: the prime partners, who in turn are expected to support the sub-grantee IPs. The unanimous view of prime partners was that MEEPP has helped them to organize their data systems through strict deadlines, DQA, and feedback meetings on quality of data and coverage. However, this support does not always reach the IPs, largely because the M\&E department of some prime partners does not have a clear budget and work plan for capacity building of IPs, or because the budget is embedded in the service delivery department, where $\mathrm{M} \& \mathrm{E}$ is not always given priority.

\section{What Has Been the Impact on the National M\&E Capacity?}

MEEPP does not have an explicit mandate to build the capacity of GOU agencies in M\&E. Despite USG procurement of other means of supporting GOU HIV and health M\&E, there still appears to be a gap in this capacity. MEEPP is reported to have provided some capacity building in M\&E to GOU and has involved MOH staff in DQA activities.

\section{In Summary, What Are the Lessons that Can Be Learned and What Aspects of the Project May Need Change?}

\section{There is no clear strategy for engaging public sector stakeholders.}

This evaluation suggests that MEEPP's mandate is well understood by stakeholders and that it has largely achieved its goal of providing high quality and timely data on PEPFAR-funded activities to the Country Team. However, respondents expressed concerns that the MEEPP design inadequately considered how MEEPP would promote and ensure access of this data to key decision makers in Uganda. Despite ad hoc efforts by MEEPP and other USG activities to support GOU M\&E capacity, this gap requires further attention in the planning of any follow-on projects. In particular, MEEPP's performance monitoring indicators should include the extent to which its data are used for host country decision making.

\section{Data from non-PEPFAR-supported civil society organizations working outside health facilities tend to be excluded.}

While it is not the responsibility of MEEPP to collect data from non-PEPFAR-supported service providers, the lack of this strategic information represents a gap in the understanding of PEPFAR about current coverage of services in Uganda. 


\section{Recommendations}

This end-of-project evaluation has shown that MEEPP is largely a successful project that has met its contractual obligation. Perhaps the greatest challenge MEEPP has experienced is weak GOU M\&E systems both at national and district levels, as MEEPP was intended to be integrated into these M\&E systems, which are supposed to coordinate all M\&E efforts including those of USG agencies. This section of the report proposes recommendations that USG could consider in a follow-on project to address these GOU needs. The recommendations, which result from extensive discussions with MEEPP, are offered in the context of existing USG efforts to support HMIS and UAC. However, it should be noted that, for these efforts to yield tangible outcomes, the $\mathrm{MOH}$ must provide leadership by encouraging district authorities to coordinate the collection of data from their health facilities and community-based services.

\section{In Designing a Follow-on Project, USAID Should Aim to Move From An "Emergency Mode" and Align It With the National Systems of Data Collection and Reporting.}

Specifically, the follow-on project should:

1. Contribute to the current USG effort to develop and support GOU databases: In the transition phase, the follow-on project should build technical capacity of UAC and Resource Center to establish and operate web-based databases. This capacity building should be phased in with at least one year of direct support followed by targeted or selective support in subsequent years.

2. Begin to hand over operation of the MEEPP database: After appropriate training, it is feasible to transfer the MEEPP database to a prime partner or GOU. It is important, however, that this process starts soon with ensuring that only one primary data collation tool is used at the sites by MEEPP, HMIS and other agencies.

3. Contribute to the current USG support for the establishment of a national HIV and AIDS database that incorporates all HIV and AIDS data in Uganda: This database should be managed by UAC with capacity building from MEEPP during a transition phase. UAC is the appropriate location because it has the national mandate to coordinate and monitor all HIV and AIDS activities in the country. This process has already begun at UAC with USG funding through the just-ended ACE project and Population Council.

4. Support the use of existing national tools and ensure that all PEPFAR-funded partners report through both the existing national systems and to USG: There is need for USG and other donors to facilitate completion of revision and standardization of all existing HIV/AIDS GOU data collection tools in different intervention areas. The recent process of revising tools addressed a number of needs and interests of stakeholders; however, some tools (especially the clinical management tool) are not yet standardized. Using these standardized tools, the data should then be collated in a 
user-friendly format (e.g., Excel). In addition, the follow-on project should ensure that data from PEPFAR-supported sites are relayed in a timely manner to the district, UAC, and HMIS. Similarly, the project should promote the value of collecting, analyzing, and using data for district-level planning and decision making.

USG has provided technical assistance to UAC to develop a strategy for rolling out its PMMP, which covers 58 national-level indicators and 47 district-level HIV/AIDS program indicators. According to the draft report of this technical assistance, the rollout will include both national- and district-level approaches. At the district, the UAC will train a team of key officials, lead by the HIV/AIDS Focal Point Person, to collate data from service delivery sites using a district-level tool, and this information will be passed on to UAC at the national level. The MEEPP follow-on project should link into this proposed approach by supporting and participating in the harmonization of indicators and the use of one tool, which the sites can use to report to USG and the District AIDS Focal Point Person concurrently.

In the PMMP roll-out, it is also proposed that, at the national level, UAC plays a more effective leadership role in ensuring line ministries report their M\&E data to UAC. The technical assistance report makes a number of recommendations including: increasing engagement with stakeholders, creating reporting schedules, providing clear reporting mechanisms, specifying who should provide information, following-up with sector persons, and developing a spreadsheet that automatically indicates which indicators are out of date. USAID should ensure that the MEEPP follow-on project supports UAC to develop a database that allows line ministries to report to UAC.

5. Streamline and support M\&E systems of prime partners to ensure that they can, in turn, support their sub-grantee IPs: For example, the follow-up project to MEEPP should support and monitor prime partners to ensure that they provide systematic M\&E support to IPs at peripheral sites. This element could be included in the DQA process that MEEPP provides to prime partners.

\section{USAID should consult with MOH, UAC, and other host-country users of data on PEPFAR-funded activities data to devise ways to address their needs and ensure optimal utilization in policy making and program planning.}

Ideally, all requests for data and ad hoc analysis should be sent to UAC, and GOU users should receive quarterly reports from UAC. However, in the short-term or transition phase, this should be done by MEEPP while simultaneously providing systematic and targeted capacity building for UAC to assume this responsibility. In the medium- and long-term, MEEPP should build the capacity of UAC to respond directly to these requests for data and specific analysis. 
Recognizing that MEEPP has so far concentrated on the monitoring aspects of M\&E, USG should work with GOU and other partners to strengthen the current outcome evaluation framework.

In Uganda, HIV/AIDS evaluation relies on occasional national surveys and specific epidemiological studies carried out by various research groups. The report on technical assistance to UAC to roll-out the PMMP recommends that UAC, $\mathrm{MOH}$, and partners develop a strategy for national level surveys. USG should provide support to GOU to ensure this strategy is realized. 


\section{Appendix 1: Documents Reviewed}

Makumbi, Frederick, et al. 2009 (In Print). “Technical assistance to the Uganda AIDS Commission for operationalisation of the performance monitoring and management plan.” New York: Population Council.

Monitoring and Evaluation of Emergency Plan Progress (MEEPP) Project. 2010. Description of MEEPP on web site of Social \& Scientific Systems, Inc. Accessed January 26, 2010. www.meepp.or.ug

. 2009. "Monitoring and Evaluation of Emergency Plan Progress (MEEPP) Uganda, December 2004-December 2009.” PowerPoint presentation, October 2009.

2009. "Summary of MEEPP from December 2004 to 2009.”

2009. MEEPP Quarterly Reports for 2005 to 2009 (second quarter). Unpublished. Accessed September 10, 2009. www.meepp.or.ug

2009. PEPFAR Semi-Annual Reports (SAR) for the years 2006 to 2008 for the following USG agencies: Department of Defense, Peace Corps, Department of State, U.S. Agency for International Development, and Centers for Disease Control, on the MEEPP web site. Unpublished. Accessed September 10, 2009. www.meepp.or.ug

- 2009. PEPFAR Annual Program Reports (APR) for the years 2006 to 2008 for the following USG agencies: Department of Defense, Peace Corps, Department of State, U.S. Agency for International Development, and Centers for Disease Control, on the MEEPP web site. Unpublished. Accessed September 10, 2009. www.meepp.or.ug

- 2009. Semi-Annual Program Results and Explanatory Notes for the period 2005 to 2008 on the MEEPP web site. Unpublished. Accessed September 10, 2009.

www.meepp.or.ug

- 2009. Annual Program Results and Explanatory Notes for the period 2005 to 2008 on the MEEPP website. Unpublished. Accessed September 10, 2009. www.meepp.or.ug

2008. "Report of NUMAT Data Quality Assessment and Data Validation Report for Data Submitted in the EP FY07 Annual Report.” Unpublished.

U.S. President's Emergency Plan for AIDS Relief (PEPFAR). 2009. PEPFAR Overview on web site. http://www.pepfar.gov

2008. Uganda Fiscal Year 2008 Country PEPFAR Operational Plan (COP). http://www.pepfar.gov 
2007 (Unpublished). The President’s Emergency Plan for AIDS Relief: Indicators, Reporting Requirements, and Guidelines Indicators Reference Guide, FY2007 Reporting/FY2008 Planning.

Uganda Program for Human and Holistic Development (UPHOLD). 2007. “Quarterly Report, January to March 2007.” http://uphold.jsi.com 


\section{Appendix 2: Questionnaires}

\section{Master Guide for Key Informant Interviews and In-depth Interviews}

1. How would you describe MEEPP as an organization?

What was MEEPP set up to do?

How does MEEPP work?

How would you describe the MEEPP design?

To what extent has the MEEPP design incorporated the use of action-oriented research and special studies to supplement routine service delivery statistics in informing decision makers?

Who are MEEPP's clients? Who does MEEPP serve? Who benefits from the services of MEEPP?

2. How has MEEPP enhanced the availability of HIV/AIDS M\&E data?

How well does MEEPP present results from PEPFAR-supported activities in usable formats, e.g., mapping that can inform the PEPFAR Country Team's programming decisions?

How well does MEEPP meet PEPFAR reporting deadlines for semiannual and annual reports?

What is the extent to which MEEPP reports to PEPFAR are accessible to GOU, IPs, and non-USG development partners (e.g., whether sent automatically or only on demand)?

What is the extent to which data from PEPFAR-funded activities has informed programming at national at the level of PEPFAR Country Team and Technical Working Groups (TWGs)?

3. What has been the effects/impact of the MEEPP project on the M\&E capacity of PEPFAR/Uganda and its IPs?

What is the evidence regarding strengthened monitoring and reporting systems of PEPFAR/Uganda and its IPs?

What role has MEEPP played in enhancing the M\&E capacity of PEPFAR/Uganda and its IPs?

To what extent are IPs able to interpret their M\&E data and extract implications for programs and policy?

How has MEEPP contributed to enhancing the capacity of IPs to analyze and make use of M\&E data?

How has MEEPP interacted with the other M\&E systems of the USG such as CDC, Infotronics, MEMS, and others?

4. What were MEEPP's expectations with regard to strengthening of local M\&E capacity?

How has MEEPP interacted with the national M\&E system?

What has been the effects/impact of the MEEPP project on the national /local M\&E capacity?

What is the spillover effect of the MEEPP system in enhancing the capacity of the 
national M\&E system to capture data from multiple sources at the national and district level on a regular, formal basis while limiting dual reporting?

How well does the system developed by MEEPP support and align with the national reporting requirements, e.g., PMMP of UAC, HMIS of MOH, OVC activities to MoGLSD?

How else has MEEPP contributed to the expansion and enhancement of the local M\&E capacity?

What has been learned and what can be improved in regard to MEEPP's interaction with the national M\&E system's development and capacity building for host-country M\&E and other specialists?

5. How well is MEEPP meeting the objective of collaboration, coordination, and harmonization?

How has MEEPP contributed to improved coordination and collaboration among USG agencies and IPs?

How has MEEPP contributed to harmonization of data sets across partners and beyond USG?

To what extent has MEEPP improved coherence of USG's EP portfolio, e.g., training of IPs on common data/indicator definitions in order to ensure data comparability, collation, and adjustments for double counting?

6. What is the level of satisfaction of MEEPP's clients with the services provided by MEEPP?

What are the views of the PEPFAR IPs on the benefits of the MEEPP system with regard to the programming cycle of their services including planning, implementation, and evaluation?

What are the views of the staff of USG agencies regarding the benefits of the system developed by MEEPP in terms of planning, coordination, implementation, monitoring, and harmonization of the USG support to the Ugandan response to the epidemic?

What are the views of GOU agencies on how MEEPP contributed to national planning, coordination, implementation, and monitoring of the HIV/AIDS response, as well as the extent to which MEEPP assists the UAC to collate data on the national response to HIV/AIDS?

How successful was MEEPP in communicating with constituencies including USG, GOU, and civil society organizations both in extracting information and in disseminating findings?

Has the system developed by MEEPP motivated or de-motivated service providers to routinely report service delivery statistics?

What is the client feedback regarding communication style, satisfaction, and capacity building?

To what extent did MEEPP involve the key stakeholders when developing this system? Is there more appreciation for data demand and information use or is the focus on reporting numbers reached, regardless of the quality of services offered? And what has been the role of MEEPP in this aspect?

\section{Overall would you say MEEPP is meeting its objectives?}

Overall, was the MEEPP project implemented as designed? 
Overall, was the MEEPP design able to address the M\&E needs of PEPFAR and GOU?

\section{What external factors may have affected MEEPP's success in attaining the} results?

Physical factors such as internet connectivity and power outages PEPFAR requirements and pressures on implementing partners

GoU M\&E systems and their ability to co relate with MEEPP's systems

9. In general, what lessons have been learned from the MEEPP experience?

What worked well?

What didn't work well?

What needs to be scaled up in the new project?

What should be new additions in the new project?

What challenges need to be addressed by the new project and how?

What is the added value of an activity similar to MEEPP to HIV programming and policy development in Uganda?

What factors influenced the usefulness of the information from the system developed by MEEPP? For example: the nature of information collected; burden of data collection; sources of the information; timeliness of reports; packaging and level of disaggregation of the information reported?

How could the value of the information be enhanced?

Overall, what are the best practices demonstrated by the MEEPP project?

Overall, what gaps can be indentified in the current project? And what aspects of the project may need change in order to address these gaps? 


\section{Checklist for Observation of Data Management System}

\section{How has MEEPP enhanced the availability of HIV/AIDS M\&E data?}

What is the status of electronic databases with regard to: comprehensiveness, interoperability with national systems, ease of use, actual use, and plans /feasibility for handing over to appropriate institution once project is ended?

How well does MEEPP present results from PEPFAR-supported activities in usable formats, e.g., mapping that can inform the PEPFAR Country Team's programming decisions?

How well does MEEPP meet PEPFAR reporting deadlines for semiannual and annual reports?

What is the extent to which MEEPP reports to PEPFAR are accessible to GOU, IPs, and non-USG development partners (e.g., whether sent automatically or only on demand)?

What is the extent to which data from PEPFAR-funded activities has informed programming at national and PEPFAR Country Team levels?

Review of the MEEPP database for:

- ease of inputting data from and by IPs

- ease of use for key analyses and generation of reports

- flexibility to generate reports by geographical regions, type of service, type of IP, period of time, etc.

- accessibility of data sets for use by GOU agencies

- adaptability of the MEEPP Partner Reporting System by the GoU and other stakeholders

- potential for sustainability of the data base beyond USG funding and the existence of MEEPP

2. Over the last five years, has there been an improvement in the quality of data reported by IPs to the Office of Global AIDS Coordinator?

How does the data meet the set technical standard of PEPFAR reporting?

What has been the trend of quality of data reported to OGAC over the last five years? Over the past five years, to what extent were the reports timely, met the set technical standards, and complete per PEPFAR indicators?

What measures were taken by MEEPP to avoid double-reporting across all program areas and how successful were they?

What is the balance of emphasis between data on treatment and prevention?

What is the balance of emphasis between facility-based versus community-based data? What is the balance in focus between monitoring vs. evaluation?

3. What has been the effects/impact of the MEEPP project on the M\&E capacity of PEPFAR/Uganda and its IPs?

What is the status of electronic databases with regard to: inter-operability with other USG systems, ease of use, actual use, and plans for handing over to an appropriate institution once project is ended? 
4. What were MEEPP's expectations with regard to strengthening of local M\&E capacity?

What is the status of electronic databases with regard to: inter-operability with national systems, ease of use, actual use, and feasibility for handing over to an appropriate institution once project is ended?

5. How well is MEEPP meeting the objective of collaboration, coordination, and harmonization?

To what extent is the MEEPP system able to collate data from the different USG team M\&E systems, e.g., Civil Society Fund and USAID/Uganda’s Monitoring and Evaluation Management Services (MEMS)?

How accessible is the MEEPP database for use by USG agencies? 


\section{Appendix 3: Prime Partners Reporting for Annual Program Report 2007}

\section{USAID-funded Prime Partners}

1. Aid Conservation through Education (ACE)

2. Access, Quality, and Use in Reproductive Health (ACQUIRE)

3. AFFORD

4. AFRICARE

5. Association of Volunteers in International Service (AVSI)

6. Basic Education and Policy Support-Presidential Initiative on AIDS Strategy for Communicating to Young People (BEPS-PIASCY)

7. Canadian International Development Agency (CIDA)

8. CAPACITY Project

9. Children AIDS Fund

10. Christian AID

11. Communities Responding to the HIV/AIDS Epidemic (CORE)

12. Community Resilience and Dialogue (CRD)

13. Conflict Districts

14. Catholic Relief Service (CRS) -TRACK I

15. DELIVER

16. Elizabeth Glaser Pediatric AIDS Foundation (EGPAF)

17. Family Health International (FHI) -SAFE STOP

18. Hope for African Children Initiative (HACI)

19. Health Communication Partnership (HCP)

20. HIV -READERS

21. Hospice Uganda

22. International Youth Foundation

23. Inter-Religious Council of Uganda (IRCU)

24. Joint Clinical Research Center (JCRC)

25. John Snow International (JSI)

26. Legislative Support Activity (LSA)

27. Monitoring and Evaluation of the Emergency Plan Progress (MEEPP)

28. Opportunity International-Uganda Agency for Development Limited

29. ORC MACRO

30. PART BUSINESS

31. Program for Appropriate Technology in Health (PATH)

32. People Living with HIV/AIDS (PHA) Network

33. PLAN International

34. POLICY II

35. Quality Assurance Project- University Research Co (QAP -URC)

36. Salvation Army

37. Samaritan's Purse

38. Program for Human and Holistic Development (UPHOLD)

39. World Vision 


\section{CDC-funded Prime Partners}

1. AIDS Information Center

2. AIDS Relief

3. African Medical And Research Foundation (AMREF)

4. Baylor College of Medicine-Pediatric Infectious Diseases Clinic (PIDC)

5. Integrated Community Based Initiatives (ICOBI)

6. Jhpiego

7. Kalangala Local Government

8. Kumi Local Government

9. Mildmay International

10. Ministry of Health

11. Medical Research Council (MRC)

12. Makerere University, Kampala School of Public Health

13. Faculty of Medicine-Mulago Mbarara Joint AIDS Program (MJAP)

14. PACE

15. Protecting Families Against HIV/AIDS (PREFA)

16. Research Triangle Institute (RTI)

17. Strengthening HIV Counseling (SCOT)

18. The AIDS Support Organization (TASO)

19. Uganda Blood Transfusion Services

20. Uganda Virus Research Institute (UVRI)

21. Uganda Prisons Services

22. University of California, San Francisco

\section{Prime Partners Funded by Department of Defense and Department of State}

1. Uganda Peoples Defence Force (UPDF)

2. Makerere University Walter Reed Program (MUWRP)

3. International Medical Corps (IMC)

4. International Rescue Committee (IRC)

5. Small Grants 


\section{Appendix 4: Matrix for Selecting Prime Partners and Implementing Partners Sample}

\begin{tabular}{|c|c|c|c|c|c|c|c|c|c|c|}
\hline $\begin{array}{l}\text { PROGRAM } \\
\text { AREAS }\end{array}$ & $\begin{array}{l}\text { AFFORDI } \\
\text { JHU/CCP } \\
\text { (USAID) }\end{array}$ & $\begin{array}{l}\text { AFRICARE } \\
\text { (USAID) }\end{array}$ & $\begin{array}{l}\text { AIDS } \\
\text { Info } \\
\text { Centre } \\
\text { (CDC) }\end{array}$ & $\begin{array}{l}\text { AIDS Relief } \\
\text { ICRS } \\
\text { Consort } \\
\text { (CDC) }\end{array}$ & $\begin{array}{l}\text { AMREF } \\
\text { (CDC) }\end{array}$ & $\begin{array}{l}\text { Conflict } \\
\text { DistrictsI } \\
\text { NUMAT } \\
\text { (USAID) }\end{array}$ & $\begin{array}{l}\text { EGPAF } \\
\text { (USAID) }\end{array}$ & $\begin{array}{l}\text { IRCU (Includes } \\
\text { IRCU follow on } \\
\text { targets) - } \\
\text { (USAID) }\end{array}$ & $\begin{array}{l}\text { Joint Clinical } \\
\text { Research } \\
\text { Center/ TREAT } \\
\text { Follow on/TBD } \\
\text { (USAID) }\end{array}$ & $\begin{array}{l}\text { MJAP } \\
\text { (CDC) }\end{array}$ \\
\hline РMTCT & & & & & & & $\begin{array}{l}\text { Kampala } \\
\text { Mulago }\end{array}$ & & & \\
\hline CT & & & & & & & & & Mbale & Mbarara \\
\hline $\begin{array}{l}\text { Other } \\
\text { Prevention }\end{array}$ & Kampala & & & & & & & & & \\
\hline ovc & & Ntungamo & & & & & & & & \\
\hline $\begin{array}{l}\text { Palliative } \\
\text { Care-TB }\end{array}$ & & & & & & & & & Tororo & $\begin{array}{l}\text { Kampal } \\
\text { a }\end{array}$ \\
\hline
\end{tabular}




\begin{tabular}{|c|c|c|c|c|c|c|c|}
\hline $\begin{array}{l}\text { PROGRAM } \\
\text { AREAS }\end{array}$ & $\begin{array}{l}\text { PEACE } \\
\text { CORPS }\end{array}$ & $\begin{array}{l}\text { PHA NetworkI } \\
\text { International } \\
\text { HIVIAIDS } \\
\text { Alliance - } \\
\text { (USAID) }\end{array}$ & $\begin{array}{l}\text { PIDC_Baylor } \\
\text { College } \\
\text { Uganda- } \\
\text { (CDC) }\end{array}$ & $\begin{array}{l}\text { Plan } \\
\text { International } \\
\text { IHACI (USAID) }\end{array}$ & $\begin{array}{l}\text { PREFA / TORORO } \\
\text { CHILD COHORT - } \\
\text { (CDC) }\end{array}$ & RTI - (CDC) & $\begin{array}{l}\text { UPDF-DEPARTMENT } \\
\text { OF DEFENSE }\end{array}$ \\
\hline ART & & & Gulu & & & & \\
\hline РMTCT & & & & & Tororo & & \\
\hline CT & & & & & & & \\
\hline Lab & & & & & & & \\
\hline $\begin{array}{l}\text { Abstinence \& } \\
\text { Being } \\
\text { Faithful }\end{array}$ & Mubende & & & & & & Bombo \\
\hline $\begin{array}{l}\text { Other } \\
\text { Prevention }\end{array}$ & & & & & & & \\
\hline OVC & & & & Luwero & & & \\
\hline $\begin{array}{l}\text { Palliative } \\
\text { Care-TB }\end{array}$ & & & & & & & \\
\hline $\begin{array}{l}\text { Palliative } \\
\text { Care-Basic }\end{array}$ & & Mukono & & & & Mpigi & \\
\hline
\end{tabular}




\begin{tabular}{|l|l|l|l|l|l|}
\hline & \multicolumn{1}{|l|}{$\begin{array}{l}\text { IRC } \\
\text { (State) } \\
\text { PROGRAM } \\
\text { AREAS }\end{array}$} & $\begin{array}{c}\text { State } \\
\text { Small } \\
\text { Grant } \\
\text { (State) }\end{array}$ & $\begin{array}{c}\text { TASO } \\
\text { (CDC) }\end{array}$ & $\begin{array}{c}\text { UVRI } \\
\text { (CDC) }\end{array}$ & $\begin{array}{c}\text { Walter } \\
\text { Reed }\end{array}$ \\
\hline ART & & & Mbarara & & Kayunga \\
\hline PMTCT & & & & & \\
\hline CT & & Kampala & & & \\
\hline Lab & & & & Gulu & \\
\hline $\begin{array}{l}\text { Abstinence \& } \\
\text { Being Faithful }\end{array}$ & & & & & \\
\hline $\begin{array}{l}\text { Other } \\
\text { Prevention }\end{array}$ & Masindi & & Kampala & & \\
\hline OVC & & & & & \\
\hline $\begin{array}{l}\text { Palliative Care- } \\
\text { TB }\end{array}$ & & & Masaka & & \\
\hline $\begin{array}{l}\text { Palliative Care- } \\
\text { Basic }\end{array}$ & & & & & \\
\hline
\end{tabular}

